La revolución desde las instituciones: la participación de la Tendencia Revolucionaria en la gobernación de Buenos Aires (1973). Un aporte para el análisis de la política no armada en los años setenta Fernanda Tocho

\title{
La revolución desde las instituciones: la participación de la Tendencia Revolucionaria en la gobernación de Buenos Aires (1973). Un aporte para el análisis de la política no armada en los años setenta
}

\author{
The revolution from the institutions: the participation of the \\ Revolutionary Tendency in the government of Buenos Aires \\ (1973). A contribution to the analysis of unarmed politics in the \\ 1970s.
}

\author{
Fernanda Tocho \\ Instituto de Investigaciones en Humanidades y Ciencias Sociales; \\ Universidad Nacional de La Plata (Argentina) \\ fernandatocho@yahoo.com.ar
}

\footnotetext{
Resumen

El artículo analiza el proceso de institucionalización de la militancia revolucionaria peronista en la gobernación de Oscar Bidegain en el año 1973, una temática que ha sido marginada de los análisis historiográficos dominantes sobre los años setenta en función de la primacía otorgada al activismo armado. A través de la reconstrucción empírica del amplio repertorio de prácticas legales, partidarias e institucionales que desplegaron los/las funcionarios/as de la Tendencia Revolucionaria en los ministerios y secretarías bonaerenses, se busca iluminar aspectos poco conocidos del pasaje de la militancia peronista inscripta en organizaciones armadas a las estructuras del Estado, y los sentidos renovados que sobre la revolución, la democracia y la construcción del socialismo nacional pusieron en juego sus protagonistas, observando también las diferencias y tensiones que este proceso despertó entre la conducción de FAR y Montoneros en función de la preponderancia otorgada a la vía armada. Más allá de estas tensiones, el enfoque propuesto busca complejizar el esquema interpretativo binario que desde la literatura académica y testimonial ha tendido a presentar como lógicas dicotómicas y excluyentes las practicas armadas y las iniciativas legales desplegadas por la militancia revolucionaria peronista de Esta obra está sujeta a la Licencia Reconocimiento-NoComercial-CompartirIgual 4.0 Internacional de Creative Commons. http://creativecommons.org/licenses/by-nc-sa/4.0/

(cc) BY-NC-SA
} 


\title{
Fernanda Tocho
}

aquellos años. En este sentido, el artículo propone pensar otras dinámicas de funcionamiento y articulación posibles -no sin tensiones- entre las acciones legales/institucionales y las prácticas armadas desarrolladas en el seno de la Tendencia Revolucionaria en la coyuntura democrática.

\section{Palabras Clave}

Tendencia revolucionaria peronista; lucha armada; institucionalización; estado; democracia; revolución.

\begin{abstract}
This article analyzes the process of institutionalization of the revolutionary Peronist militancy in the Oscar Bidegain governorate in 1973, a theme that has been marginalized from the dominant historiographic analyzes of the 1970s based on the primacy given to armed activism. Through the empirical reconstruction of the wide repertoire of legal, partisan and institutional practices that the officers of the Revolutionary Tendency deployed in the Buenos Aires ministries and secretariats, it seeks to illuminate little-known aspects of the passage of the Peronist militancy registered in organizations armed to the structures of the State, and the renewed senses that the protagonists put into play in the unprecedented experience of state management about revolution, democracy and the construction of national socialism, also observing the differences and tensions that this process aroused in the leadership FAR and Montoneros and the preponderance given to the armed route. Beyond these tensions, the proposed approach seeks to complicate the binary interpretive scheme that, from the academic and testimonial literature, has tended to present, as dichotomous and excluding logics, the armed practices and legal initiatives deployed by the revolutionary militancy of those years. In this sense, the article proposes to think about other possible dynamics of functioning and articulation - not without tensions - between legal / institutional actions and armed practices developed within the Revolutionary Tendency.
\end{abstract}

\section{Keywords}

Peronist revolutionary trend; armed struggle; institutionalization; state; democracy; revolution.

\section{Introducción}

El 25 de mayo de 1973 Oscar Bidegain asumió como gobernador de la provincia de Buenos Aires acompañado por un centenar de militantes de la Tendencia Revolucionaria del Peronismo (TR) que ocuparon cargos de primera y segunda línea en su gabinete, llevando a cabo durante los 8 meses de su gestión un ambicioso programa de políticas públicas ancladas en el imaginario de construcción del "socialismo nacional".

Este fenómeno, el de la institucionalización en el Estado de grupos de la militancia revolucionaria peronista, durante largo tiempo fue relegado dentro del campo historiográfico orientado predominantemente por un enfoque que Omar Acha ha denominado "violentología", es decir, una matriz interpretativa profundamente 


\section{La revolución desde las instituciones: la participación de la Tendencia Revolucionaria en la gobernación de Buenos Aires (1973). Un aporte para el análisis de la política no armada en los años setenta}

reduccionista que se centra en la violencia política como clave explicativa del proceso político argentino de los años setenta (Acha, 2010) y, en consecuencia, en la primacía de la lucha armada como expresión unívoca de la política revolucionaria de aquellos años.

Incluso este mismo sesgo analítico sobrevuela también en aquellas investigaciones que repararon en el fenómeno de las llamadas "provincias montoneras" (Servetto, 2010; Antúnez, 2015) y en parte de la bibliografía testimonial (Peyrou, 2010; Duzdevich, Raffoul y Beltramini, 2015). En su conjunto, estos trabajos han tendido a interpretar la participación de la militancia revolucionaria sólo en términos instrumentales, en función de la lucha de poder que mantenían con los sectores de la derecha peronista y para obtener recursos que fortalecieran la estrategia militar, sin encontrar otras motivaciones político-ideológicas más de fondo en ese accionar. De este razonamiento se desprende la idea de que no existió un proyecto político de la TR para el gobierno, quedando reducidas estas experiencias al plano de la contienda política discursiva más que al de las prácticas, o en su defecto, completamente subsumidas a la lógica armada.

En el presente artículo nos proponemos poner en debate estos postulados, a través de la reconstrucción empírica y el análisis de un amplio repertorio de prácticas legales, partidarias e institucionales que desplegaron los/las funcionarios/as de la TR en el gobierno bonaerense, con el objetivo de iluminar aspectos poco conocidos del pasaje de la militancia peronista inscripta en organizaciones armadas a las estructuras del Estado. Tomamos como caso la gobernación de Oscar Bidegain ya que fue allí donde mayor desarrollo alcanzó el despliegue de los grupos de la Tendencia a nivel de Ministerios y Secretarías.

El estudio pormenorizado de la dinámica de funcionamiento de algunos ministerios en los que estuvieron al frente los/as militantes-funcionarios/as, posibilitará incorporar experiencias relativamente marginadas del análisis histórico dominante sobre el periodo que se abre en 1973 , observando un proceso mucho más rico en metodologías de acción, que exceden con creces las prácticas armadas, y un conjunto sustantivo de políticas públicas que se inscribieron plenamente -para algunos/as de sus protagonistas- en un horizonte democratizante y revolucionario desde las instituciones. Esto a su vez nos permitirá, por un lado, poner en debate algunos postulados que en la literatura presentan las acciones legales desplegadas por los grupos de la TR como un universo escindido y contradictorio per se respecto de la estrategia de lucha armada trazada por las organizaciones político-militares. Por el contrario, una de las hipótesis que sostendremos es que la participación electoral y la intervención en el gobierno -a partir del GAN- fue definida por la militancia revolucionaria peronista como una táctica, es decir, un instrumento válido de lucha política dentro de un conjunto más amplio de acciones que se inscribían todas ellas en una estrategia mayor de guerra integral nunca abandonada por las organizaciones armadas. Por otro lado, observaremos como esta experiencia 


\section{Fernanda Tocho}

concreta de militancia en el Estado desarrollada por los/las integrantes de la Tendencia que ocuparon cargos en el gobierno provincial comenzó a ser resignificada por estos sujetos como un momento central y una práctica sustancial del proceso revolucionario mismo, cargando así de nuevos sentidos la apuesta institucional, proceso que no estará exento de tensiones respecto de la preponderancia otorgada a la vía armada desde la conducción de FAR y Montoneros.

\section{Punto de partida: "Política vs Guerra". Algunas reflexiones sobre el estado de la cuestión}

Como mencionamos brevemente, el tratamiento que durante largo tiempo caracterizó los estudios sobre "los años setenta" y el complejo periodo de 19731976, se centró fundamentalmente en tópicos como la violencia política, la militarización de los conflictos y la primacía de la lucha armada (Oberti-Pittaluga, 2006; Acha, 2010). La mayor parte de estas investigaciones emprendidas en la post dictadura - y fuertemente influidas por la teoría de los dos demonios y el espíritu de la transición- tendieron a reducir la complejidad de la década precedente bajo el prisma de la polarización analítica y política de "autoritarismo/democracia". En esta clave, tanto el activismo armado protagonizado por las organizaciones políticomilitares, como la experiencia del gobierno democrático iniciada en 1973 quedaron bajo el velo común del "autoritarismo" y el imperativo de la violencia que habría caracterizado la cultura política de esos años, obstruyendo así la posibilidad de recuperar otras aristas de ese proceso histórico que permitan su comprensión (por ejemplo, la dimensión no armada de la práctica revolucionaria).

Esta dificultad no sólo atravesó a los estudios académicos de la década del ochenta, sino que también estuvo presente en abordajes historiográficos posteriores y en los relatos de parte de la militancia. En particular, las tesis sobre el "militarismo" de Montoneros (Slipak, 2015:14-15) y la consiguiente "sustracción de la política" por el imperativo de la violencia, tendieron a ocluir aspectos centrales de la experiencia institucional que desarrolló su militancia y la relevancia que cobró la apuesta electoral en las lecturas, posicionamiento y prácticas que desplegó dicha organización (Svampa, 2003; Calveiro, 2005; Ollier, 2005; Bartoletti, 2011). Algunas de las obras mencionadas tienden a observar como fenómenos dicotómicos, la existencia de un activismo legal presente en un amplio sector de la militancia de base (la lógica política), de las prácticas armadas (la lógica de la guerra) que habrían imperado en la cúpula de la organización y que explicarían su derrota.

El mismo argumento, del predominio de la militarización por sobre la búsqueda de la construcción política, aparece también en gran parte de la bibliografía testimonial crítica sobre la trayectoria de la organización (Gasparini, 1999; Amorín, 2005; Pastoriza, 2006). En la mirada retrospectiva de algunos/as ex militantes, las experiencias gubernamentales de la TR aparecen reducidas a un "episodio fugaz", meramente simbólico y dentro del plano de las expectativas y los discursos, más que 


\section{La revolución desde las instituciones: la participación de la Tendencia Revolucionaria en la gobernación de Buenos Aires (1973). Un aporte para el análisis de la política no armada en los años setenta}

de las prácticas. En particular, este tipo de registro se encuentra en los testimonios del grupo de militantes que rompieron con Montoneros y formaron "JP Lealtad" a principios de 1974, en los que el paradigma de la militarización y la "transmutación ideológica" que habría conllevado la fusión con las FAR, actúan como un tamiz interpretativo que tiende a minimizar el peso de la apuesta institucional desarrollada en diversos momentos, calificando ese proceso como "poco significativo" en algunos casos, o como "falso" e "impostado" desde la Conducción Nacional de Montoneros, en otros (Amorin, 2005; Peyrou, 2010; Duzdevich, Raffoul y Beltramini, 2015).

Con todo, algunos trabajos académicos más recientes han logrado ampliar el marco analítico en cuestión a través de la reconstrucción de fenómenos políticos extracéntricos durante el tercer gobierno peronista, poniendo en el centro de la escena la participación de la TR en las denominadas "gobernaciones montoneras". Los trabajos de Bonavena (2009), Servetto (2010) y Antúnez (2015) reconstruyen el papel fundamental que sus organizaciones desempeñaron durante la campaña electoral y dentro de la interna partidaria en distintas regiones, como también la incorporación de sus militantes en la gestión iniciada en 1973, y el lugar preponderante que jugó ese vínculo -real o imaginado- entre los gobernadores y la TR, en la crisis terminal de estos gobiernos ante la ofensiva desatada por la derecha del Movimiento y el propio Perón.

Más allá de estos valiosos aportes que desde un enfoque regional permiten reponer la presencia extendida de la militancia peronista revolucionaria en espacios y funciones no circunscriptas a las prácticas armadas, en este conjunto de trabajos observamos nuevamente la primacía de una matriz interpretativa que postula el "espiral de violencia", la "militarización de la política" y la "lógica de guerra" como las únicas claves explicativas del conflicto interno en el peronismo y el fracaso de las experiencias de gobierno ligadas a la TR.

A modo de ejemplo de estas interpretaciones, Servetto (2010) explica los conflictos de la interna peronista en las provincias como resultado de la "lucha por espacios de poder condensados en el aparato estatal", y de un enfrentamiento en términos discursivos sobre quien detentaba el monopolio de la identidad peronista: "la lucha se medía en términos morales: leales contra traidores...Aquí no se trató de un enfrentamiento entre dos proyectos; por el contrario, ambos sectores revelaron carecer de proyectos para orientar la acción estatal. Sus preocupaciones se limitaban a reclamar cargos y espacios de poder" (p. 202-203). ${ }^{1}$

Por último, cabe mencionar el libro de Pozzoni (2017) que reconstruye las diversas formas de participación política de las juventudes de la izquierda peronista en la

\footnotetext{
${ }^{1}$ Un enfoque muy similar, que pone el énfasis en el carácter discursivo del conflicto entre la derecha y la izquierda del Movimiento -por sobre la distinción de las prácticas y proyectos políticos en juegoes el de Antúnez (2015), para quien la ofensiva desatada contra los gobernadores "montoneros" respondía menos al desafío por izquierda que sus programas y prácticas de acción política pudieran representar, y más a una lógica de enfrentamiento violento por espacios de poder desde 1972.
} 


\section{Fernanda Tocho}

provincia de Buenos Aires durante la primera mitad de la década del setenta, destacando en particular las iniciativas no armadas. Bajo esta perspectiva, la autora pone de relieve el compromiso de diversas figuras y grupos de la TR en el activismo electoral, reponiendo el trabajo de militancia universitaria, sindical, barrial y en las movilizaciones de la campaña que llevaron al triunfo de Bidegain, como también su posterior intervención en diferentes ámbitos del gobierno. En este marco, Pozzoni indaga las discusiones que emergieron el seno de la TR en esa coyuntura, entre los militantes que finalmente conformaron la disidente "JP Lealtad" y Montoneros. Según la autora, las diferencias centrales pasarían por la posición más movimientista y defensora de acciones "más políticas" representada por los integrantes de Lealtad, en contraposición con la línea "más militarista" -y por ende, no política- de Montoneros y FAR.

Nuevamente encontramos en este esquema -al igual que en la perspectiva de los/as autores mencionados previamente- una caracterización de los actores y del proceso político en cuestión que remite a una división binaria y excluyente entre dos lógicas opuestas atravesando su accionar: la de la política (entendida solamente en su dimensión formal-institucional) por un lado, y la de la guerra (en su versión de vanguardia militarista) por otro, encontrando allí un nudo de contradicciones que actuarían desde el origen como un limitante esencial en la consecución de la experiencia de gobierno de la TR. ${ }^{2}$

Como síntesis de estas perspectivas, se desprende la imposibilidad de pensar la realización exitosa -e incluso la existencia misma- de un proyecto de gestión encarado por la militancia de la Tendencia en el marco de un proyecto revolucionario de más largo alcance que incluía la lucha armada. Esto en términos epistemológicos, obtura la posibilidad de reconocer analítica y empíricamente, en la particular coyuntura histórica de 1973, la existencia de otras dinámicas de funcionamiento y articulación posibles -no sin tensiones- entre las acciones legales/institucionales y las prácticas armadas en el seno de la TR.

En el siguiente apartado, reconstruiremos la trayectoria institucional de los militantes de la TR que ocuparon cargos en la gobernación bonaerense con el objetivo de comprender el repertorio amplio de prácticas, proyectos de gestión y programas que efectivamente pusieron en juego sus integrantes, cuestiones que exceden ampliamente la simple dicotomía discursiva, la lógica de guerra imperante o la puja instrumental de cargos entre la "patria peronista" versus la "patria socialista".

Por otra parte, si bien la atención estará puesta en las acciones legales encaradas por estos grupos, las mismas se analizarán teniendo en cuenta la estrategia de lucha armada trazada por este actor, observando así en la coyuntura de esos años la racionalidad de ciertas apuestas políticas en la que lo institucional, lo revolucionario

\footnotetext{
2 Una perspectiva similar puede encontrarse en el artículo pionero de Lenci (1999) sobre la disyuntiva de la TR ante las elecciones de marzo 1973
} 


\section{La revolución desde las instituciones: la participación de la Tendencia Revolucionaria en la gobernación de Buenos Aires (1973). Un aporte para el análisis de la política no armada en los años setenta}

y lo armado no necesariamente fueron pensados -por gran parte de los sujetos involucrados en estos procesos históricos- como elementos excluyentes.

\section{La llegada de la TR al gobierno provincial: militancia revolucionaria $y$ experticia profesional}

Luego del triunfo del FREJULI en las elecciones del 11 de marzo, que dieron la victoria en Buenos Aires a la fórmula de Oscar Bidegain y Victorio Calabró, una de las cuestiones más urgentes a resolver fue la necesidad de constituir los planteles dirigenciales para completar las carteras ministeriales. Este era un punto muy importante si tenemos en cuenta que se venía de 18 años de proscripción por parte del peronismo, careciendo así de un equipo funcionarial con continuidad en el Estado que viniera trabajando previamente.

En la provincia, la relación entre Bidegain y la TR se había afianzado durante las movilizaciones de la campaña electoral, constituyéndose la Juventud Peronista (JP) en la única base de apoyo del gobernador, hecho que le permitió contrarrestar el peso del aparato de CGT y de la UOM volcado en los actos proselitistas a favor de Calabró (Antúnez, 2015; Tocho, 2019). Estas circunstancias, más el apoyo de Perón para llevar a cabo en el ámbito bonaerense una prueba del trasvasamiento generacional (Urriza, 2004:62; Pozzoni, 2017) -y la militancia sus dos hijas, Gloria y Cristina Bidegain, y su yerno, Daniel Vaca Narvaja en JP/Montoneros- fueron las que promovieron el lugar preponderante de la TR en el gabinete, ocupando los cargos de primera y segunda línea en los Ministerios de Gobierno, Asuntos Agrarios, Bienestar Social, Obras Públicas, en la Subsecretaría de Cultura y Educación y en otras dependencias provinciales (Tocho, 2020)

La gran cantidad de espacios en los que intervinieron y las funciones públicas de peso en las que se desempeñaron, nos habla de un heterogéneo grupo de figuras y militantes que contaban con diversos derroteros dentro del peronismo revolucionario, portadores de experiencias ricas y plurales de trabajo técnico y militancia dentro del Movimiento. A continuación, describiremos sucintamente los recorridos previos de algunos grupos para tener una caracterización más precisa de estos/as militantes en su rol de agentes ministeriales (Osuna y Vicente, 2017) y de las hibridaciones entre su militancia política y sus saberes profesionales.

El primer grupo es el Consejo Tecnológico (CT) del Movimiento Nacional Peronista, cuyos integrantes ocuparon los principales puestos en la Asesoría del Consejo Provincial de Desarrollo (ASPRODE) que dependía directamente de Gobernación, y en los Ministerios de Asuntos Agrarios y Obras Públicas de la provincia. El CT fue fundado a principios de los setenta por el físico Rolando García, quien había sido desplazado de su cargo de decano de la Facultad de Ciencias Exactas y Naturales de 


\section{Fernanda Tocho}

la UBA en "La noche de los bastones largos". ${ }^{3}$ Este grupo incluía a reconocidos especialistas de diversas áreas quienes venían trabajando en la elaboración de proyectos promotores de las condiciones para la liberación nacional y social, y cuyos postulados y profesionales se identificaron con la TR y con el "Socialismo Nacional". 4 Según la prensa de la época, el CT de García representaba "la expresión del nuevo peronismo, el de la juventud" cuya "irrupción en la conducción de la economía nacional constituiría una verdadera revolución, mediante la redistribución de los ingresos, la reforma agraria, la nacionalización de los bancos extranjeros y del comercio exterior". ${ }^{5}$ Las formulaciones de sus proyectos sobre políticas públicas se publicaron en la colección semanal "Bases para un Gobierno Peronista" que salió entre los meses de marzo y julio de $1973 .^{6}$

El segundo grupo, el más numeroso, estuvo formado por el núcleo de militantes de la Federación Universitaria de la Revolución Nacional (FURN), agrupación estudiantil peronista de la UNLP ligada directamente a la JP de La Plata, Berisso y Ensenada y al Movimiento Revolucionario Peronista (MRP). Este grupo que ocupó lugares importantes en los Ministerios de Asuntos Agrarios y Bienestar Social, y en la Subsecretaría de Hacienda, se caracterizó por la formulación previa en el ámbito universitario de propuestas que apuntaban a una formación profesional "al servicio del pueblo", desterrando de la Universidad el colonialismo cultural y los intereses a favor del imperialismo, ${ }^{7}$ como así también por el trabajo territorial en la zona (creación de Unidades Básicas) y la apuesta temprana por el trabajo político partidario en el contexto de apertura electoral. Estas iniciativas, cabe señalar, se realizaban en paralelo con otras apuestas y definiciones políticas sostenidas por este

\footnotetext{
${ }^{3}$ Formalmente, el lanzamiento del CT se hizo en julio de 1972, más allá de que se viniera trabajando en su armado desde mucho tiempo antes. Ver Ciencia Nueva, $\mathrm{N}^{\circ}$ 18, agosto de 1972 "El Consejo Tecnológico del Movimiento Nacional Justicialista". Agradezco a Sergio Friedemann la información y consulta de esta revista.

${ }^{4}$ García invitó a varios profesionales de diversas ramas y confió la secretaría al ingeniero Héctor Abrales. Junto a Mario Hernández, Lepanto Bianchi, Carlos Abeledo, Julio Villar, Héctor Recalde, Hugo Di Florio, Enrique Martínez, Ricardo Ferraro, Emilia Ferreiro (esposa de Rolando García), Horacio y Eduardo Bauer, Alberto González, Guillermo Gallo Mendoza, Floreal Ferrara, Ricardo Rubio y Marina Siri, entre otros. Poco después Jorge Taiana quedó a cargo de la vicepresidencia, por pedido de Cámpora, aun cuando sus diferencias con García eran constantes. Ver Bonasso (2010:215 y 243), Friedemann (2017), Pozzoni (2017) y Dip (2017). “Biografías del peronismo revolucionario: Rolando García" en http://www.robertobaschetti.com/biografia/g/292.html.

${ }^{5}$ La Opinión, 13/3/1973 "Versiones fidedignas" y La Opinión, 20/3/1973 "El gremialismo y los jóvenes frente al próximo gobierno justicialista". A la par del CT, otros grupos de similares características, pero con diferentes orientaciones político-ideológicas fueron promovidos por Perón para desarrollar propuestas de gobierno. Tal es el caso del Consejo de Planificación del Movimiento Nacional Justicialista (CPMNJ) liderado por Leopoldo Frenkel y Roberto Ares, identificado con sectores de la derecha del Movimiento (Denaday 2018) y el Comando Tecnológico Peronista de Julián Licastro y José Luis Fernández Valoni ubicado en el centro del espectro político del peronismo.

${ }^{6}$ Se encuentran disponibles en el repositorio digital http://www.ruinasdigitales.com

${ }^{7}$ Entrevista de la autora a Hugo Bacci (2012). Una muestra de las aspiraciones políticas y la proyección de gestión en el ámbito público por parte del grupo FURN se observa en el Documento Bases para la Nueva Universidad, analizado por Lanteri-Meschiany (2015) Dip (2017) y Barletta (2018)
} 


\section{La revolución desde las instituciones: la participación de la Tendencia Revolucionaria en la gobernación de Buenos Aires (1973). Un aporte para el análisis de la política no armada en los años setenta}

grupo JP/FURN, como la defensa de la lucha armada y la integración a la organización político-militar Montoneros por esa misma época (Tocho, 2020). ${ }^{8}$

Un tercer grupo que ocupó lugares preponderantes en el Ministerio de Gobierno, Bienestar Social y en la Subsecretaría de Cultura fue el que venía de la organización político-militar Descamisados (luego fusionada con Montoneros), que reunía a militantes del mundo cristiano y peronista radicalizado, con experiencias previas de trabajo social y territorial en villas del Gran Buenos Aires (alfabetización y organización comunitaria) y gremial (colaboración en los equipos de la CGTA), inclinándose también por la participación y disputa dentro de las estructuras del Movimiento sin abandonar en paralelo sus prácticas armadas. ${ }^{9}$

Por último, los/as integrantes de los Equipos Político-Técnicos (EPT) de la Juventud Peronista. Este grupo estuvo formado por militantes montoneros de Capital Federal, muchos de los cuales venían de las FAP “oscuros”, y habían ingresado a Montoneros a mediados de 1971, quienes también tenían experiencia previa de militancia en ámbitos universitarios (Cátedras Nacionales, FANDEP), sindicales (CGTA) y profesionales (CTMNJ). Ocuparon roles destacados en el Ministerio de Asuntos Agrarios, en Obras Públicas, en la Subsecretaría de Cultura dependiente del

${ }^{8}$ Entrevista de la autora a Gonzalo Chaves (2016) y Nora Peralta (2012). Nos referimos a que a fines de 1972 se produce la integración de este grupo importante militantes platenses a la organización Montoneros, en paralelo a su militancia partidaria a nivel local y provincial, llevando candidatos propios, y a su activa participación en la organización de la campaña electoral. Esa doble lógica política que combinaba las formas institucionales y las armadas, en sus comienzos, era experimentada sin mayores tensiones por los/as integrantes de este grupo. Así lo recuerda Nora Peralta, fundadora de la FURN y militante de JP/Montoneros: "Ias elecciones no eran el objetivo final porque a través de éstas era muy difícil poder lograr un cambio revolucionario, pero de todas formas nos metimos en esa opción, en ese trabajo, porque estratégicamente eran importantes, participar ahí porque era una buena forma de difusión de nuestra línea política. En ese momento éramos JP, la fusión con Montoneros vino después a fines del 72. Hubo acuerdo en integrarnos, como militantes de base sentíamos la necesidad de cambiar los métodos de lucha porque a través de las elecciones había quedado claro que era muy difícil lograr el objetivo de la liberación real y la lucha armada estaba legitimada a nivel mundial con la Revolución Cubana, Argelia. Es decir, nosotros íbamos por el cambio, era liberación o dependencia, y creíamos que uniendo ambas cosas íbamos a lograr tomar el poder económico, no solo estar en el gobierno".

${ }^{9}$ Entrevista de la autora a Flora Castro, La Plata (2013). Flora a partir del año '64 fue coordinadora de la "Campaña mundial de lucha contra el Hambre", un programa que dependía de la Iglesia Católica en el que se aplicaba la pedagogía de Paulo Freire y las ideas de Ezequiel Ander Egg sobre Desarrollo de la Comunidad y Organización Popular, en barrios de Villa Martelli. Esas actividades sociales progresivamente se fueron combinando con otras acciones más políticas y con el despliegue de la lucha armada desde la organización Descamisados. Así lo menciona: "Esa inserción territorial digamos fue más para la cuestión política de las elecciones, y para formar cuadros para el gobierno, y también para la organización armada porque bueno... yo no venía a eso, pero sí venía Norberto, Ojea Quintana, Soler, ellos hacían todo un trabajo que tenía que ver con la incorporación de cuadros a la JP, JTP, UES, y cuando se vio que se podían presentar a elecciones se pensó en la posibilidad de conseguir un candidato que respondiera a lo que planteaba el peronismo revolucionario". Como vemos, el trabajo territorial y la posición "movimientista" sostenida por Descamisados a favor de las elecciones y de dar la pelea dentro de las estructuras legales del peronismo contra los sectores burocráticos, se articulaba en la organización con el planteo más estratégico de guerra integral que apostaba a continuar con la lucha armada como método efectivo para la toma del poder. Ver "Carta abierta de Montoneros y Descamisados: A los Compañeros de la Juventud en el día de los fusilamientos", junio de 1972, disponibles en El Topo Blindado. Tocho (2020) 


\section{Fernanda Tocho}

Ministerio de Educación (Pozzoni, 2015) y en la Dirección de Menores del Ministerio de Bienestar Social. El lanzamiento formal de los EPT se realizó en abril de 1973, luego del triunfo electoral. En la conferencia de presentación, Alcira Argumedo, figura central de esta experiencia, los caracterizaba como "una instancia más del poder popular gestado desde las bases. Donde lo elaborado no es una asesoría más sino un nuevo canal para la estrategia propia de la Juventud en su camino hacia la patria socialista". Asimismo, Argumedo aclaraba que el atraso en la presentación de las propuestas -más de un mes después de la victoria en los comicios- se debía a que "sobre la JP recayó el peso de las movilizaciones contra la dictadura militar. Los EPT son el producto de esas luchas de las bases y reciben una línea política de esas luchas. No son mera tarea de gabinetes y tecnócratas".10

A propósito, esta última referencia permite acercarnos a los sentidos y representaciones que acompañaron ese pasaje a la gestión estatal por parte de la militancia revolucionaria, en donde si bien el "componente técnico-profesional" era valorado como un saber y un requisito necesario, se privilegiaba la experiencia política de activismo y militancia revolucionaria en los frentes de masas de la etapa inmediatamente anterior. Al respecto, este "capital militante" (Poupeau, 2007) ${ }^{11}$ del que gozaban los miembros de la TR devenidos en funcionarios/as de gobierno, los hacía portadores de un "conjunto de saberes, disposiciones" y valores ético-políticos que en el contexto de la época eran sumamente estimados, inclusive más que las credenciales académicas que pudieran demostrar (o que al menos debían estar indisociablemente combinadas con ellas). De esta forma, ese conjunto de "saberes y habilidades" adquiridas en el quehacer de la militancia "en el llano" y durante largos años de resistencia a la dictadura, se convertían ahora en insumos claves que moldeaban sus prácticas de gestión institucional y que, en la percepción de los y las militantes, "garantizaban" la continuidad de su compromiso político revolucionario, ahora en el Estado. ${ }^{12}$

Estas ideas serán las que guíen las políticas desplegadas por los/as funcionarios/as de la TR en el gobierno provincial, articulando de modo particular los

\footnotetext{
${ }^{10}$ La Opinión, 28/4/1973 “Proyectos de los seis equipos técnico-políticos” y La Opinión, 24/4/1973 "Creará la Juventud Peronista su propio equipo técnico-político".

${ }^{11}$ Para este autor, el capital militante implica en su estado incorporado: "un conjunto de técnicas, de disposiciones a actuar, intervenir, o simplemente obedecer; recubre un conjunto de saberes y de saberhacer movilizables durante acciones colectivas, luchas inter o intra-partidarias, pero también exportables, convertibles en otros universos, y, así, susceptibles de facilitar ciertas 'reconversiones"' (Poupeau, 2007: 40-41). En este sentido, podría pensarse en la trayectoria de los/as militantes de la TR que ocuparon cargos en el Estado como un caso de traslación del capital militante al campo de la gestión pública. Un ejemplo del uso y aplicación de estas categorías puede verse en el artículo de Chama y González Canosa (2011) sobre la participación de militantes de la JUP en la Facultad de Derecho de la UBA en 1973.

${ }^{12}$ Esta asunción de la condición militante y revolucionaria por encima de su rol técnico-profesional está presente también en la declaración de los integrantes del CTMNJ, quienes se describen así mismos como hombres "que no son, pues, tecnócratas que intentan elaborar planes para el Movimiento, sino revolucionarios conscientes que desde el Movimiento abordan, con profundo sentido nacional, los problemas del país". Ciencia Nueva, $\mathrm{N}^{\circ}$ 18, agosto de 1972 "El Consejo Tecnológico del Movimiento Nacional Justicialista". Agradezco a Sergio Friedemann la consulta de esta revista.
} 


\section{La revolución desde las instituciones: la participación de la Tendencia Revolucionaria en la gobernación de Buenos Aires (1973). Un aporte para el análisis de la política no armada en los años setenta}

requerimientos técnicos y específicos de cada área con aquellos valores, metodologías y saberes asumidos en su militancia revolucionaria.

Como mencionamos previamente, dentro del conjunto heterogéneo de agrupaciones que integraban la TR, la posibilidad de participar de las elecciones y del futuro gobierno se había expresado siempre en términos tácticos, como un medio secundario o una herramienta que servía a un fin mayor (la constitución de un ejército revolucionario para la toma del poder). Esta concepción instrumental de las formas legales de lucha política será una constante por parte de las organizaciones armadas peronistas a lo largo de todo este período.13

No obstante, con el horizonte democrático en ciernes y ante la movilización cada vez mayor de amplios sectores juveniles interpelados por la posibilidad de las elecciones y el retorno del peronismo, los métodos de legales de lucha comenzaron a considerarse como acciones de pleno derecho que se incorporaban al repertorio legítimo de prácticas promovidas por las organizaciones revolucionarias del peronismo en esa coyuntura, adquiriendo los así denominados "métodos revolucionarios secundarios" un rol cada vez más preponderante. ${ }^{14}$

A continuación, ahondaremos en los sentidos que los/las militantes de la TR involucrados en las tareas de gestión provincial les atribuyeron a esas iniciativas institucionales, observando cómo la intervención cotidiana en el Estado comenzó a ser resignificada por estos sujetos, adquiriendo -para algunos/as de sus protagonistas- un valor en sí mismo, ya no como un medio o una tarea secundaria, sino como un objetivo más sustantivo de acumulación y transformación política a los fines revolucionaros.

\footnotetext{
${ }^{13}$ FAR y Montoneros "Apoyar, Defender y Controlar", Comunicado del 24/05/1973 ante la asunción de Héctor Cámpora, en Baschetti (1996:49-51). Y FAR y Montoneros “Construir el poder popular", El Descamisado, Año 1, № 4, 12 de junio de 1973, pp.2-4. En este reportaje Quieto y Firmenich marcaban la diferencia sustantiva entre "asumir el gobierno" y "tomar el poder", dejando en claro que la victoria en las elecciones constituía sólo una etapa dentro de la "guerra revolucionaria" de más largo alcance. Esta concepción de la lucha armada como política estratégica, para los dirigentes debía plasmarse también en la composición del nuevo gobierno, al que además de tener que "defender" de los posibles intentos golpistas, debían también "custodiar y controlar de eventuales desviaciones" que impidieran "el cumplimiento de la liberación como etapa de transición hacia la construcción del socialismo nacional". Esto concretamente se lograría sólo a través "del reconocimiento (en el nuevo gobierno) de las estructuras que hagan efectiva la participación de las masas en la resolución de los conflictos...y por medio de las organizaciones político-militares".

${ }^{14}$ Este salto se dio a partir del lanzamiento de los famosos "Cinco Puntos" que Montoneros adoptó como programa político en la mayor parte de sus comunicados del año 1972, apoyando el proceso electoral y levantando la candidatura de "Perón Presidente". Ver "Comunicado de Montoneros: Al Pueblo de la Nación", diciembre de 1971; "Comunicado de Montoneros: A los compañeros trabajadores", marzo de 1972; "Carta abierta de Montoneros y Descamisados: A los Compañeros de la Juventud en el día de los fusilamientos", junio de 1972, disponibles en el sitio web El Topo Blindado.
} 


\section{Fernanda Tocho}

\section{Los “Ministerios rojos"15}

\section{Ministerio de Bienestar Social:16}

La gestión de este Ministerio quedó en manos del Floreal Ferrara, un reconocido médico sanitarista, discípulo de Ramón Carrillo y amigo personal de J.W. Cooke, con una larga trayectoria intelectual y política en el campo de la salud y en el peronismo revolucionario (Tocho, 2014 y 2020). ${ }^{17}$

Rápidamente, luego de la asunción, comenzaron a hacerse visibles los ejes que atravesarían su gestión: acción directa, activismo popular y democratización en la gestación y despliegue de las políticas públicas del sector.

A modo de ejemplo, durante los primeros días de su gobierno y en el contexto general de "las tomas" (Abbattista y Ramírez, 2011) Ferrara junto al equipo de funcionarios/as de la TR promovieron una serie de medidas y prácticas que -además de focalizarse en políticas sociales y sanitarias a favor de los sectores más postergados- oficializaron y potenciaron la concurrencia de las bases en la toma de decisiones y en la orientación de las políticas promovidas desde el Ministerio.

En este marco, a principios de junio, se llevó a cabo una multitudinaria movilización de la JP de La Plata, Berisso y Ensenada hacia la "República de los Niños" ubicada en las afueras dela ciudad, ocupando sus instalaciones. El objetivo de la toma era devolver el contenido social y cultural que en su momento había inspirado la creación del predio por parte de la Fundación Eva Perón, dejando sin efecto la concesión en manos privadas que hasta ese momento tenía la explotación del lugar.

\footnotetext{
${ }^{15}$ Con esa denominación "bautizaron" desde las páginas de la revista El Caudillo a los Ministerios bonaerenses encabezados por figuras de la Tendencia. El Caudillo, Año 2, № 8, 4/01/1974. "La Gobernadora y sus muchachos" y "Terrorismo y sabotaje contra el gobierno de Perón: Gallo Mendoza: un ministro ignorante" p. 15 y 16. En la primera de estas notas se hace referencia al papel preponderante que habría desempeñado la esposa de Bidegain, junto con sus hijas, en el armado del gabinete y la política de "infiltración marxista" llevada a cabo en la provincia, cuestionando a su vez la "pasividad" del gobernador frente a estos hechos. Para un análisis de esta publicación ver Besoky (2010)

${ }^{16}$ Por cuestiones de extensión en este artículo abordaremos de manera sucinta sólo tres ministerios, dejando fuera el caso del Ministerio de Gobierno cuya labor amerita un análisis pormenorizado. Parte de su actividad fue analizada en Tocho (2018) con motivo del Operativo Dorrego.

${ }^{17}$ Otros vínculos significativos en esta adscripción, y por la misma época, fueron la amistad que entabló con los principales referentes del sindicalismo combativo en los años de la resistencia peronista (Avelino Fernández, Sebastián Borro y Andrés Framini) a través de su labor de asesoría en el manejo de las obras sociales de los sindicatos, denunciando tempranamente la corrupción de ciertos dirigentes. Hacia fines de los '60, participó de la experiencia de la CGTA y colaboró activamente en los equipos de trabajo del CTMNJ en el área de salud. Por su parte, y de forma paralela, fue su cargo como Profesor en la Cátedra de Medicina Preventiva y Salud Social en la UNLP el espacio específico que lo vinculó con los jóvenes militantes de FURN-JP/Montoneros y desde allí su nombre fue sindicado a Bidegain para ocupar el cargo de Ministro de Bienestar Social en la provincia. Svampa (2010:59 y ss), Arrúa (2014). La relación entre Ferrara y los jóvenes de FURN/JP es señalada por varios de nuestros entrevistados. Alejandro Peyrou menciona a Ferrara como parte de los nombres que se postularon en el famoso organigrama, dada su pertenencia al peronismo revolucionario y su participación en los equipos técnicos del peronismo. Carlos Flaskamp, militante de las FAR, destaca que a principios de los '70 Ferrara figuraba en una lista de médicos cercanos a las organizaciones guerrilleras con los cuales se podía contar en casos de emergencia. Ver Biografías del Peronismo Revolucionario: Floreal Ferrara http://www.robertobaschetti.com/biografia/.
} 


\section{La revolución desde las instituciones: la participación de la Tendencia Revolucionaria en la gobernación de Buenos Aires (1973). Un aporte para el análisis de la política no armada en los años setenta}

Estas acciones se hicieron con el apoyo oficial del Ministerio de Bienestar Social de la provincia, organismo que se haría cargo de la intervención y gestión del inmueble hasta su definitiva expropiación. ${ }^{18}$

La toma de la República de los Niños constituyó uno de los eventos donde se expresaron las nuevas formas de intervención política de la militancia aglutinada en la Tendencia en esta coyuntura. En ella se materializaron los nuevos ritmos, metodologías y sentidos de la política puestos en juego por este actor, en los que la urgencia por llevar a cabo transformaciones de envergadura y poner fin al "continuismo" de la dictadura, se articuló con prácticas de acción directa y una fuerte presencia del actor popular en la gestación de esas acciones y en el sentido de esos cambios. Todo esto bajo el paraguas de la participación institucional de sus militantes en el gobierno, quienes alentaban estas acciones como una forma de aportar y fortalecer el proyecto de construcción del "socialismo nacional".19

En este sentido, podemos afirmar que estos episodios de acción colectiva permiten evidenciar los intentos por conjugar las metodologías revolucionarias con las nuevas funciones gubernamentales asumidas por los/las militantes de la TR, ampliando los límites de la democracia representativa otrora denostada, hacia nuevos horizontes de participación e intervención social.

Volviendo al episodio de la toma, en el comunicado que brindó la JP se señalaba la continuidad de este tipo de acciones, dado que ellas representaban "el modo más eficaz de afianzar la participación popular en el futuro gobierno [siendo] la recuperación de la República una de las plataformas de lanzamiento de las 'Comisiones Pro-Defensa del triunfo' constituidas para actuar mancomunadamente con las autoridades populares". ${ }^{20}$ Estas Comisiones, organizadas por la militancia barrial de la JP en articulación con los funcionarios/as de la TR en el Ministerio, se habían lanzado con el objetivo de actuar como puntos de apoyo, control y defensa del gobierno a nivel local y provincial, canalizando las inquietudes de la población y ampliando las instancias de participación popular en diferentes ámbitos estatales (Tocho, 2014 y 2020). ${ }^{21}$

\footnotetext{
18 Entrevista de la autora a Nora Peralta (2012) participante de la toma. El Día, 4/6/73, "Fueron ocupadas las instalaciones del País de los niños en Gonnet”. Según la crónica del diario, más de 5000 personas participaron de esta toma. Además de la amplia militancia de base de la JP, participaron también funcionarios provinciales y dirigentes de la TR, convocados especialmente para concretar la ocupación del lugar: la Subsecretaria de Seguridad Social, María Esther Méndez San Martín; Flora Castro, Directora de Promoción y Desarrollo de la Comunidad; Amalia Ramella, militante del núcleo FURN/Montoneros y Directora de Servicios Sociales; los diputados provinciales por la JP Carlos Negri y Héctor Moreda, el diputado nacional Carlos Kunkel, y el delegado de la Regional 1 de la JP Carlos Cafferata, quienes refrendaron el acta de ocupación. Incluso de la toma participó también la esposa del gobernador Bidegain, María Antonia Moro. En ese acto, Raúl Piñeyro, militante del núcleo FURN/Montoneros fue nombrado su Interventor.

19 Entrevista de la autora a "Cacho", M. (2016). Entrevista de la autora a Nora Peralta (2012), Hugo Bacci (2012) y Babi Molina (2014). También expresiones de este tipo pueden encontrarse en Jauretche (1997) y Perdía (1997).

${ }^{20}$ El Día, 4/6/73, "Fueron ocupadas las instalaciones del País de los niños en Gonnet".

${ }^{21}$ Entrevista de la autora a Baby Molina (2014). Entrevista de la autora de Hugo Bacci (2012)
} 


\section{Fernanda Tocho}

Esta iniciativa se desarrollaba en consonancia con el accionar de las "Juntas Vecinales de Consumidores" (JUVECO) que reunían a vecinos de todos los barrios, quienes se organizaban para impedir las actividades de acaparamiento, especulación y artificial desabastecimiento promovido por algunos empresarios y miembros de la cadena de comercialización, actuando a la vez como dispositivo inmediato de control de los precios máximos fijados por el gobierno. ${ }^{22}$

Más allá del alcance y el accionar efectivo que lograron estas iniciativas (las Comisiones y las Juntas), lo que es difícil de estimar, cabe destacar que ambas gozaban del reconocimiento oficial, lo que expresaba el notable activismo que atravesaba a importantes sectores de la sociedad y los intentos por parte de la TR de formalizar esa participación popular desde el Estado, a través de la creación de nuevas instancias y mecanismos institucionales que tendían a acortar las distancias entre "pueblo" y "gobierno".

Estas acciones se replicaron en otros establecimientos públicos, por nombrar sólo uno, tomaremos el caso de la toma del Hospital de Quilmes. Allí, hasta el 25 de mayo de 1973, la gestión interna y financiera del hospital estaba en manos del Consejo Médico Asesor y de las "Damas de Beneficencia”. Luego de la asunción de Ferrara, una asamblea encabezada por los trabajadores del hospital, la Agrupación 17 de Noviembre perteneciente a Sanidad y miembros de la JP, JTP y el Movimiento Villero Peronista (MVP), decidió tomar el establecimiento, nombrando nuevas autoridades y la conformación de una Mesa de Trabajo y Reconstrucción que llevaría adelante un programa de transformación de la atención sanitaria brindada a la comunidad. ${ }^{23}$

Este tipo de políticas que tendían a desterrar las jerarquías entre los médicos y el resto de los trabajadores de la salud, promoviendo la participación activa de la comunidad en la decisión de los programas de atención médica, se implementó no solo en la gestión de los hospitales provinciales, sino que se desarrolló a nivel de los centros de salud local. Una de las principales propuestas que desplegó Ferrara consistió en un novedoso plan de descentralización de la atención sanitaria, a través de la formación de Hospitales de comunidad y su instalación en barrios periféricos y zonas marginales de toda la provincia. Estas "pequeñas unidades de salud participativa" como él las llamaba, contarían con el trabajo de un equipo

\footnotetext{
22 Decreto del PE provincial, no 32/73. El Día, 2/6/73 "Fueron creadas en la provincia las Juntas Vecinales de Consumidores" En varias notas de El Descamisado se describen las tareas realizadas por estas Comisiones de control de precios y comercialización. Ver "Canasta familiar: Defenderse, movilizarse, no dejarse robar". El Descamisado, $\mathrm{N}^{\circ}$ 5, 19/6/73, p. 10.

${ }^{23}$ Parte de las medidas dispuestas por este nuevo órgano de gestión fueron: establecimiento de la gratuidad de la atención sanitaria y entrega de remedios a los pacientes (en contraposición a la atención paga y las prestaciones privadas vía mutuales que solían realizar los médicos en la gestión anterior); supresión de todos los aranceles en los consultorios externos y en internación; prohibición de que los médicos perciban en horarios de trabajo otros honorarios que no sean los que correspondían por su labor en el establecimiento; disolución del Consejo Médico Asesor y reasignación de sus honorarios para el mejoramiento de la atención a los pacientes más necesitados; establecimiento de una guardia pediátrica permanente; eliminación de los intermediarios (alimentos, insumos, placas radiográficas, etc); uso del comedor gratuito por los familiares de los pacientes, etc. Este modelo fue replicado en otros hospitales de la provincia, despertando todo tipo de resistencias y críticas de la corporación médica aglutinada en FEMEBA (Tocho, 2020)
} 


\section{La revolución desde las instituciones: la participación de la Tendencia Revolucionaria en la gobernación de Buenos Aires (1973). Un aporte para el análisis de la política no armada en los años setenta}

interdisciplinario de profesionales y trabajadores de la salud (médicos, antropólogos, psicólogos, enfermeros, trabajadores sociales) y con un consejo de la comunidad integrado por los habitantes de la región, que tendría intervención directa en la toma de decisiones y el manejo de la institución. ${ }^{24}$

Precisamente este aspecto de la organización comunitaria y la participación popular en todos los niveles de la atención médica "que implican tanto el trabajo, la planificación, la ejecución, la evaluación y el control de la acción sanitaria por parte del pueblo", 25 constituían una pieza importante del programa que Ferrara venía diseñando meses atrás, como parte de las propuestas de políticas públicas para el sector, considerando esta modalidad de funcionamiento horizontal y asambleario la mejor vía para contrarrestar el proceso de desmantelamiento y burocratización que azotaba la atención hospitalaria en la provincia desde hacía 18 años atrás. ${ }^{26}$

Un punto substancial del programa de Ferrara -el que más controversias y a la vez expectativas despertó- fue su política de lucha contra el monopolio y extranjerización de la industria farmacéutica, planteando como horizonte de mediano plazo la nacionalización de la producción y comercialización de medicamentos, lo que implicaba en la práctica una dura batalla contra los capitales extranjeros que controlaban el sector. Para ello, el Ministerio firmó un convenio con la UNLP a fin de elaborar un proyecto conjunto que diseñara la implementación de una política nacional de medicamentos, propuesta que luego sería elevada a Nación (Bustingorry, 2015 y Tocho, 2020). ${ }^{27}$

Por otra parte, la intervención popular como un elemento clave del proyecto de gestión que impulsó la TR desde el Ministerio se reflejó también en los programas encarados desde la Dirección de Promoción y Desarrollo de la Comunidad a cargo de Flora Castro, junto a la Dirección de Servicios Sociales en manos de Amalia

\footnotetext{
${ }^{24}$ Ministerio de Bienestar Social. Subsecretaría de Salud Pública. Dirección de Atención Medica. Fondo documental Floreal Ferrara, Archivo de la Biblioteca Nacional. Ya desde los años '60 y a lo largo de su importante labor intelectual, Ferrara se destacó por sus ideas y escritos progresistas en el campo de la medicina comunitaria y por un enfoque multidisciplinar en torno a la atención de la salud. Tocho (2020)

${ }^{25}$ El Día, 10/06/1973 "Asumió ayer el ministro de B. Social, Dr. Floreal Ferrara".

${ }^{26}$ La Gaceta, 10/6/1973 “Ministro revolucionario para una obra revolucionaria”. Ver Luis Bruschtein, entrevista a Floreal Ferrara http://www.pagina12.com.ar/2001/01-03/01-03-05/pag14.htm. Otras políticas que complementaban estas medidas fueron la garantía por parte del Estado de la prestación gratuita de la salud a los sectores más desfavorecidos a través de la creación de un Seguro Social que garantizara una efectiva e igualitaria cobertura médica, desde la niñez hasta la ancianidad. Esta iniciativa sería acompañada por la creación de un Seguro Lácteo para todos los menores de 10 años, en especial para aquellos de las zonas de emergencia sanitaria, a través de la provisión de leche por el Estado provincial y nacional. Ver Bustingorry (2015) y Tocho (2020)

${ }^{27}$ La Opinión, 25/7/1973 "La situación sanitaria en Buenos Aires". La Nación, 25/7/1973 "Política sanitaria para Buenos Aires". Si bien por cuestiones de extensión en este artículo no podemos llevar a cabo una comparación con las políticas desplegadas por Nación para el área de Bienestar Social, es importante señalar que ese Ministerio, desde la asunción de Cámpora, estuvo a cargo de José López Rega, quien mantuvo una relación muy tensionante con Ferrara desde el inicio y en particular a partir de los episodios de Ezeiza (Svampa, 2010: 70). Para un análisis pormenorizado de la política del Ministerio de Bienestar Social entre 1966 y 1976 ver el excelente trabajo de Osuna (2017).
} 


\section{Fernanda Tocho}

Ramella, encargadas de llevar adelante programas con un fuerte contenido participativo y social en el territorio. Una de estas iniciativas fue el Proyecto de Formación de Centros de Promoción de la Comunidad que consistía en la creación de nuevos Centros Comunitarios en zonas rurales, barrios populares y villas miseria de toda la provincia, junto a la reconversión de los "viejos" centros heredados de la administración militar saliente. En ellos trabajarían asistentes sociales, profesores y maestros, personal de maestranza y particularmente los habitantes del barrio y la comunidad (Tocho, 2014 y 2020). ${ }^{28}$

En la práctica, la concreción de estos centros sirvió para dar anclaje y reconocimiento institucional a las acciones asamblearias y a las demandas cooperativistas impulsadas por la militancia barrial y juvenil previa, de muy activa participación durante la campaña electoral y organizada formalmente a partir de mayo de 1973 a través del MVP (Camelli, 2018). Una de estas iniciativas consistió en el lanzamiento de un Plan de Cooperativas de Construcción de Viviendas, elaborado conjuntamente con el MVP, e integrado por las familias villeras, quienes tendrían a su cargo las tareas de planificación, edificación y reconstrucción tanto del establecimiento público (el Centro Comunitario propiamente dicho) como de las viviendas populares mismas. Los materiales eran aportados de forma gratuita por la gobernación a través del Ministerio de Obras Públicas, mientras que la mano de obra era aportada por la comunidad residente en las villas. ${ }^{29}$ A través de este Plan se daría lugar a una de las reivindicaciones más importantes del sector villero, aquella que impulsaba la radicación de sus viviendas en el lugar que históricamente habitaban, en oposición a la política de erradicación y traslado (Camelli, 2018).

Al respecto, resultan interesantes las impresiones que sobre esta experiencia de trabajo institucional nos brindan dos de sus protagonistas, quienes lejos de ver dicha apuesta como reñida con los objetivos revolucionarios y de transformación de más largo alcance, la entendían como una oportunidad central para cambiar las estructuras "desde adentro" del Estado:

\footnotetext{
${ }^{28}$ Entrevista de la autora a Flora Castro (2013). Entrevista de la autora a Mabel Maidana (2014). Tal como mencionamos en la cita 9, estas políticas de participación comunitaria no fueron un elemento absolutamente novedoso, sino que encontraban sus antecedentes en las políticas de participacionismo cristiano que la dictadura anterior promovió desde el PEN en el marco del ideario desarrollista y católico conservador imperante durante los años cincuenta y sesenta. Ver los trabajos de Giorgi y Malimacci (2012), Giorgi (2014) y Ramaciotti (2014) al respecto. Agradezco a Florencia Osuna los comentarios lúcidos sobre estas tramas precedentes de las prácticas comunitaristas y católicas.

${ }^{29}$ Ya! Es Tiempo de Pueblo, № 10, “Organizados desde cada villa, cada manzana, cada pasillo", p. 10 y "Villeros Peronistas. Impulsar las empresas populares", p. 13. Camelli (2018). En la conferencia de prensa que se realizó con motivo del lanzamiento de este programa, el Ministro Ferrara se refería en primer lugar al contenido participativo y popular de la iniciativa "la intervención directa de los villeros en el gobierno del pueblo se hará mediante la formación de esas cooperativas de trabajo, que tienen por finalidad construir las viviendas que el pueblo reclama en las villas de emergencia, y asimismo defender el derecho que tiene cada trabajador a levantar su propia casa. Estas "empresas" estarán integradas, administradas y dirigidas por los propios villeros. Y el gobierno deberá aportar los elementos necesarios para su concreción". El Día, 18/7/1973 “Coparticipación de villeros en un programa de vivienda".
} 


\title{
La revolución desde las instituciones: la participación de la Tendencia Revolucionaria en la gobernación de Buenos Aires (1973). Un aporte para el análisis de la política no armada en los años setenta
}

\begin{abstract}
"La posibilidad de la apertura que se dio con el peronismo había que aprovecharla, ganar espacios en lo político, por eso no fue sólo con Bidegain, también Martínez Baca, Obregón Cano, Cepernic y otros con los que se intentó insertar y trabajar dentro de las estructuras de gobierno. Yo que había trabajado mucho antes con la gente en el barrio, tenía mucha inserción en Villa Martelli, y cuando se forma el gobierno y hay posibilidades de trabajar, de tener cargos, Norberto me preguntó qué me gustaría hacer, y yo le dije algo relacionado con trabajo con las villas que era lo que yo hacía... yo dije que sí porque lo que hicimos desde las bases lo podíamos hacer desde arriba...Nosotros estábamos muy de acuerdo con el trabajo político en la gobernación, con aprovechar esos espacios para generar políticas. Estaba la discusión de qué hacemos con estas estructuras ¿las combatimos o las cambiamos desde adentro? Y nosotros pensábamos que había que cambiarlas desde adentro". 30
\end{abstract}

En el mismo sentido, Mabel Maidana, militante de Montoneros que también trabajó junto a Flora Castro, señala la conexión entre diferentes espacios por los que transitaban los/as militantes de la Tendencia (el barrio/la organización/el Estado) articulando su experiencia de trabajo político-territorial con las funciones de gestión, y el lugar destacado de la organización en la línea de las políticas públicas que se implementaban y que "volvían a las bases"

\begin{abstract}
"A mí la orga me dice que tengo que ir al ministerio, después mi responsable pasa a ser el Hippie Alsogaray, y todos dependíamos de (Norberto) Habegger. Norberto tenía relación con Daniel Vaca Narvaja que se termina casando con Gloria Bidegain, y Norberto era el encargado de la conexión de la organización en la gobernación. Norberto estaba prácticamente siempre en la gobernación. Lo interesante es que había acuerdos políticos con la dirección del ministerio que estaba en manos de Ferrara, y teníamos reuniones con él y se acordaban políticas, ver qué política, con qué dirección, había una participación real en las decisiones. Y había insumos para el trabajo barrial, yo llevaba recursos para la UBR que conducía, veíamos qué cosas necesitaba la gente, muy al estilo cubano. Es decir, se vinculaban las políticas públicas con la política nuestra y con el trabajo nuestro en el barrio, con la vida cotidiana en la UBR (Unidad Básica Revolucionaria)". ${ }^{31}$
\end{abstract}

Esta articulación de las lógicas previas de militancia combativa, acción directa y trabajo en el territorio con las nuevas funciones institucionales desempeñadas en el Ministerio, y la consideración positiva e incluso prioritaria de la contribución que en su carácter de militantes-funcionarios/as podían realizar ahora desde la esfera

\footnotetext{
${ }^{30}$ Entrevista de la autora a Flora Castro (2013)

${ }^{31}$ Entrevista de la autora a Mabel Maidana (2014). Creadas a principios de 1972, las Unidades Básicas Revolucionarias (UBR) significaron una transformación sustantiva de la estructura interna de Montoneros con el fin de promover el nexo de la organización "clandestina" con la estructura de la JP Regionales, potenciando el trabajo político de sus cuadros con las agrupaciones de superficie, lo que provocó un vuelco en su crecimiento e incidencia en importantes sectores de la juventud peronista (Lanusse, 2007).
} 


\section{Fernanda Tocho}

gubernamental, se observa también en los otros casos que analizaremos a continuación.

\section{Ministerio de Asuntos Agrarios}

Al frente de este Ministerio estuvo el Ingeniero Agrónomo Guillermo Gallo Mendoza, quien había participado de diversas experiencias profesionales y políticas ligadas a la TR. Lo acompañaron el núcleo de militantes que venían de las FAP - "oscuros", como Alejandro Peyrou, y el grupo de militantes de FURN/JP de la Facultad de Veterinaria y Agronomía de la UNLP. Todos con una militancia ya dentro Montoneros a fines de 1972, lo que vehiculizó su postulación como cuadros de la organización para integrar los planteles del gobierno provincial (Tocho, 2015 y 2020). ${ }^{32}$

Precisamente en estos recorridos previos -que incluían la elaboración de proyectos en el marco del CT, la colaboración en programas de la CGTA o el diseño de propuestas elaboradas en su militancia universitaria- la cuestión de la tierra (el problema de su baja productividad, el régimen de propiedad concentrada, el sistema fiscal regresivo) había estado presente como una problemática central en las elaboraciones realizadas por estos militantes antes a su llegada al gobierno, cuestión

\footnotetext{
32 Gallo Mendoza había trabajado en el Consejo Nacional de Desarrollo (CONADE) en los años '60, combinando esa labor con su militancia en las filas de la Democracia Cristiana, espacio en el que entabló amistad con Norberto Habegger y Flora Castro. Años más tarde, ya en su tránsito al peronismo de izquierda, participó junto a ellos dos de la experiencia de la CGT de los Argentinos (CGTA), asesorando a Raimundo Ongaro en temas de política agropecuaria y vinculándose también con Alejandro Peyrou que militaba en las FAP. En 1971, desde un grupo de estudio especializado en temas agrarios (el Instituto de Estudios Sociales-IES), se incorporó al CT de Rolando García, elaborando materiales sobre políticas públicas para el sector que luego serían retomadas por diferentes agrupaciones integrantes de las Ligas Agrarias. Al año siguiente ingresó a Montoneros, y desde allí es nominado para sumarse al gabinete de Oscar Bidegain. Alejandro Peyrou estuvo a cargo de la Subsecretaría de Asuntos Agrarios, inició su militancia peronista como estudiante de la UBA donde se recibió de Licenciado en Economía. Participó también como ayudante en las denominadas "Cátedras Nacionales" de la carrera de Sociología en el año 1966, vinculándose paralelamente con la ARP de Cooke. Desde allí, en 1967 se incorporó a las FAP, y al año siguiente participó como Secretario Coordinador de los equipos técnicos de la CGTA. Finalmente, luego de las divergencias con los sectores "alternativistas" de las FAP, se integró a Montoneros en 1971, siendo uno de los que confeccionó el organigrama de cuadros político-técnicos para integrar el gobierno de Cámpora. Al frente de la Dirección de Ganadería estuvo el Médico Veterinario Hugo Bacci, quien había sido miembro fundador de FURN e integrado también la JP de La Plata, Berisso y Ensenada. Con él se sumaron a la labor en el Ministerio otros compañeros de militancia en la UNLP que ocuparon cargos relevantes: Kenneth Bar Bennett fue nombrado Subdirector de Ganadería, mientras que Gabriel Belo Soler y Carlos Miguel fueron nombrados asesores de esta área. Los cuatro se incorporaron a Montoneros luego de la fusión de JP/FURN con esa organización a fines de 1972. Desde allí, participaron activamente de la campaña electoral, reuniéndose en varias oportunidades con Bidegain. Entrevista a Guillermo Gallo Mendoza disponible en http://www.youtube.com/watch?v=NcLwLQFjVGs 20/07/2014. Entrevista a Alejandro Peyrou (2012). Hugo Bacci también corrobora la postulación de Gallo Mendoza como Ministro de Asuntos Agrarios por parte de la organización Montoneros, señalando además que él mismo participó de las reuniones en las que grupos de JP/Montoneros revisaban los curriculums y antecedentes de los posibles candidatos y su opción favorable hacia Gallo Mendoza, dado su perfil más "militante" y no "tecnócrata-desarrollista". Entrevista a Hugo Bacci (2012).
} 


\section{La revolución desde las instituciones: la participación de la Tendencia Revolucionaria en la gobernación de Buenos Aires (1973). Un aporte para el análisis de la política no armada en los años setenta}

que fue retomada como un eje fundamental de la política implementada por Gallo Mendoza y los equipos de la Tendencia.

$\mathrm{Al}$ respecto, una de las primeras medidas que se efectuaron fue la creación de las denominadas Unidades Básicas de Trabajo, Producción y Comercialización Social (UBTPCS). Las mismas consistían en la puesta en producción de predios pertenecientes a la provincia y su concesión para la explotación conjunta a familias sin tierras o campesinos minifundistas, con el doble objetivo de ayudar a los pequeños productores a alcanzar una mayor capacidad productiva, y a la vez realizar una producción con sentido social. Este programa fue implementado a través de un convenio entre los Ministerios de Asuntos Agrarios y el de Bienestar Social, dado que parte de la producción que se realizaría en esos predios (horticultura, tambo, engorde de novillos para faena) se destinaría a diversas instituciones dependientes del área de Bienestar Social (hospitales, institutos de menores, escuelas y asilos de ancianos), siendo su excedente comercializado a través de las vías normales en beneficio de los minifundistas. ${ }^{33}$ Por otra parte, a través de este tipo de unidades, se buscaba fomentar desde el Estado la producción cooperativa, estableciendo para su funcionamiento un sistema de rotación en la conducción y dirección de dichas organizaciones, "para que todos los integrantes puedan capacitarse en las funciones directivas". ${ }^{4}$ En ese marco, se promovió también la creación de un Consejo Provincial de Acción Cooperativa que reforzaba la formación de las UBTPCS en toda la región. ${ }^{35}$

Cabe señalar que esta política de distribución de tierras y su puesta al servicio de los sectores más débiles de la cadena productiva (que sí pudo efectivizarse a través de la firma del decreto provincial № 3570) formaba parte de un Proyecto de Ley Agraria más ambicioso, que se presentó a principios de la gestión de Bidegain pero que nunca llegó a tratarse formalmente en la Legislatura provincial por las presiones en su contra de las corporaciones agrarias que representaban a los grupos más concentrados del sector (CARBAP y la SRA). ${ }^{36}$ Dicho proyecto planteaba un

\footnotetext{
${ }^{33}$ Boletín Oficial de la Provincia de Buenos Aires, La Plata, Decreto 3570/73. Estas "colonias agrícolas" se desarrollaron en diversos lugares de la provincia: Pehuajó, Trenque Lauquen, Laguna de los Padres, Guaminí, 25 de Mayo, 9 de Julio, Lavallol, Torquinst, Lincoln, Zonas del Delta, San Pedro, Bahía Blanca, Mar del Plata y en el Parque Pereyra. Tocho (2015 y 2020)

34 El Día, 13/08/1973 "Creación de las unidades agrarias de solidaridad social en la provincia".

${ }^{35}$ Boletín Oficial de la Provincia de Buenos Aires, La Plata, Decreto 3572/73. El Día, 20/10/1973 "Concretóse la creación del Consejo Provincial de Acción Cooperativa" Como resultado de la aplicación de esta política de recuperación de tierras, según el balance presentado por Bidegain a seis meses de su gestión, se recuperaron en total más de 10.000 hectáreas de tierras, gran parte de las cuales se pusieron a disposición de la población campesina más desprotegida, incentivando modalidades de producción asociativa y canales de comercialización directos que evitaban la intermediación y suba de precios. El Día, 14/12/1973 “Mejor que prometer es realizar". Solicitada del Gobierno de Bidegain.

36 El Día, 01/04/1973 “Preocupa a sectores rurales un supuesto plan de reforma agraria". Entrevista a Guillermo Gallo Mendoza disponible en http://www.youtube.com/watch?v=NcLwLQFjVGs 20/07/2014. Los ejes de la política agraria provincial seguían a grandes rasgos los lineamientos trazados por la política agropecuaria nacional bajo la dirección del Ingeniero Agrónomo Horacio
} 


\section{Fernanda Tocho}

programa más radicalizado en términos del régimen de tenencia de la tierra, estipulando límites concretos y restricciones a la propiedad privada, con el objetivo de garantizar su función social y la de los productores, lo que implicaba posibles expropiaciones a terratenientes absentistas. ${ }^{37}$

Otra de las políticas que despertó mayores resistencias por parte de las corporaciones empresarias del agro fue sin duda la experiencia del "Parlamento Agrario" que promovía una reestructuración radical en las estructuras de poder y representación gremial del sector. Bajo la consigna "El Agro en pie por la liberación nacional”, se reunieron a principios de agosto más de cinco mil campesinos miembros de las Ligas Agrarias de todo el centro y norte del país, ${ }^{38}$ llevando a cabo una experiencia inédita de participación de las bases y democratización de las voces en torno a la cuestión agraria, el acceso a la tierra y su producción, y que contó con el reconocimiento del gobierno provincial y la participación oficial de los funcionarios del Ministerio. ${ }^{39}$

La finalidad del Parlamento fue sintetizar en un documento las demandas y las políticas que deberían ser implementadas para dar respuesta a los problemas en particular de estos actores (Gallo Mendoza, 2010:255). Entre las conclusiones que reunía el documento final, surgidas de las diferentes exposiciones de los representantes de las Ligas, se apuntaba a la consecución de medidas radicales tales como una Reforma Agraria Integral; la nacionalización del comercio exterior con la participación de los trabajadores a través de sus organizaciones representativas (gremios, cooperativas) para su control; la descentralización de las industrias

Giberti, a cargo de la Secretaría de Agricultura y Ganadería de la Nación. Precisamente, una de las principales medidas orientadas por esta Secretaría fue la sanción de la Ley de Impuesto a la Renta Normal Potencial de la Tierra (№ 20.538), que gravaba a todas las tierras libres de mejoras o aquellas que produjesen a una rentabilidad menor a la estipulada por el gobierno, con el fin de terminar con la ociosidad productiva y lograr niveles de explotación eficientes, desalentando así las tenencias improductivas y combatiendo la especulación. Dicha Ley, en la práctica, jamás pudo ser aplicada por la enorme resistencia que opusieron las entidades agropecuarias de alcance nacional (Sociedad Rural Argentina, Federación Agraria Argentina y Confederaciones Rurales Argentinas) y provincial (Confederación de Asociaciones Rurales de Buenos Aires y La Pampa-CARBAP), y el desacuerdo por parte de sectores internos del peronismo identificados con aquéllas. Otra política fundamental de esta Secretaría que acompañaba la sanción de la ley del IRNP, fue el proyecto de Ley Agraria, que también fue duramente resistido y nunca llegó a tratarse en el Congreso. Ver Lattuada (1986) Markler (2005) Rougier y Fiszbein (2006) y Lázzaro (2013).

${ }^{37}$ Una copia del Proyecto original de Ley Agraria tal cual fue presentado en el año 1973 se encuentra disponible en Gallo Mendoza (2010:146 y ss)

${ }^{38}$ Ligas Agrarias del Noreste Argentino, las Ligas Agrarias Bonaerenses, las Ligas Agrarias Entrerrianas, el Movimiento Rural de La Rioja, los Sindicatos Rurales, Las Ligas Tamberas de Córdoba y los nucleamientos de pequeños productores de cuencas lecheras, de cultivos intensivos y miembros de las Juventudes Agrarias

${ }^{39}$ El Descamisado, N 16, 4/09/1973 “Lincoln: La tierra debe ser de los que la trabajan". Ya! Es Tiempo de Pueblo, № 10, 30/08/1973 "El interior contra la oligarquía”. El Día, 28/08/1973, "Varios temas analizó en la ciudad de Lincoln el parlamento agrario". Para el fenómeno de las Ligas Agrarias ver Militancia Peronista, Año 1, no 17 4/10/73 “Chaco: ¿qué son las ligas agrarias”, también Anzorena (1998:176). Si bien las Ligas no tenían representación político partidaria formal, sus principales delegados se referenciaban en el espacio de la TR, y en oposición a la Federación Agraria. Ya! Es tiempo de Pueblo, $\mathrm{N}^{\circ} 7$, "El despertar de los campesinos". El Parlamento deliberó en Lincoln, bajo la presencia del Ministro Gallo Mendoza y su gabinete, junto a la asistencia de legisladores nacionales y provinciales de la TR que fueron especialmente invitados. 


\section{La revolución desde las instituciones: la participación de la Tendencia Revolucionaria en la gobernación de Buenos Aires (1973). Un aporte para el análisis de la política no armada en los años setenta}

elaboradoras de la materia prima, instalándose en los sitios de producción (en particular la instalación de frigoríficos regionales); la promoción de las formas cooperativas de trabajo y su enseñanza en las escuelas rurales, y fundamentalmente: la creación de un organismo central del Estado que controlara todo el proceso de producción, industrialización y comercialización a nivel nacional (Gallo Mendoza, 2010:258, Tocho, 2020). ${ }^{40}$

Tal como mencionamos más arriba, los planteos más radicalizados dentro del conjunto de demandas expresadas por los participantes de la asamblea agraria no pudieron ser realizados por el gobierno bonaerense. ${ }^{41}$ Sin embargo, esto no impide observar las trasformaciones profundas que para este sector proyectaban los equipos de la TR en el gobierno, a la par de otras iniciativas que sí lograron ser promulgadas desde el Ministerio como parte de su política integral de tierras y beneficio a los sectores más débiles en la cadena agropecuaria: la reglamentación y aplicación efectiva del Código del Peón Rural (Ley 7616); la implantación de un Seguro Agrícola Integral para los productores afectados por las inundaciones, y la estipulación de un precio único para la leche (Decreto 3573).

\footnotetext{
${ }^{40} Y a !$ Es Tiempo de Pueblo, № 10, 30/08/1973 "El interior contra la oligarquía". En relación con el régimen de tenencia de tierras, el documento consideraba: "Que el derecho a la tierra es un derecho natural e inalienable del pueblo, que las tierras agrarias deben ser para quienes la trabajan, que el actual régimen concentrado de tenencia de la tierra es el responsable del estancamiento de la sociedad argentina, y, a la par, causa principal del despoblamiento y empobrecimiento del interior del país, que el problema argentino debe ser enfocado teniendo en cuenta las experiencias positivas de otras reformas agrarias realizadas en América Latina (...) Todo lo expuesto demuestra que es necesario realizar en el país una verdadera justicia agraria. Concretamente, creemos que no son suficientes las leyes que tiendan a incrementar la productividad de la tierra y el trabajo solamente. Exigimos que se instrumente en el país una legislación que cambie la estructura agraria mediante la sustitución del régimen de latifundio y minifundio, por un sistema justo y eficiente de propiedad, tenencia, uso y explotación de la tierra, fundado en la equitativa distribución de la riqueza. (...) Como pautas orientadoras de la política de reforma agraria sostenemos las siguientes: Expropiación de todas las tierras de capitales extranjeros; expropiación de todas las tierras de capitales mixtos, ya que bajo esta forma se enajenaron vastas superficies de los mejores suelos del país". Gallo Mendoza (2010:282).

${ }^{41}$ Luego del Parlamento Agrario, en varias solicitadas públicas CARBAP y la SRA pidieron la renuncia del Ministro y su equipo. Por su parte, las críticas también provenían desde la Federación Agraria, en tanto el movimiento de las Ligas y la experiencia del Parlamento de Lincoln le disputaron a dicha entidad la representatividad directa de los pequeños productores dentro del campo bonaerense (Entrevista a Hugo Bacci, 2012; Entrevista a Alejandro Peyrou, 2012 y Entrevista a Guillermo Gallo Mendoza disponible en http://www.youtube.com/watch?v=NcLwLQFjVGs 20/07/2014). A nivel nacional, la oposición directa de estas entidades gremiales se manifestó también en el bloqueo del proyecto de Ley Agraria presentado por la Secretaría de Agricultura de Giberti, el cual nunca pudo ser sancionado. La Nación, 15/10/1973 “Analiza CARBAP la situación del Agro", 18/10/1973 "Reunión de CARBAP", y 19/10/1973 "Estabilidad para el agro pide CARBAP". En estas notas se recogen las principales declaraciones que los representantes de CARBAP realizaron en el congreso anual de la entidad realizado en el mes de octubre. La crítica mordaz a la política agropecuaria llevada a cabo en Buenos Aires puede observarse en sus discursos, los cuales caracterizaban las medidas de Gallo Mendoza como "un ataque al agro que pareciera que apunta a la postración del campo...y a la destrucción de todo un sistema de vida", lo que obligaba a este sector a emprender "una larga y dura batalla para defender no sólo la producción agropecuaria, sino también los principios fundamentales que hacen a la esencia misma de la nacionalidad argentina".
} 


\section{Fernanda Tocho}

Asimismo, se presentaron en la Legislatura numerosos proyectos que no llegaron a tener tratamiento: la Creación del Fondo Provincial de Colonización; la creación del Libro Ganadero; la Ley de Impuesto Único Provincial a los Inmuebles Rurales; y la creación de la Junta Provincial de la Papa, entre otras (Tocho, 2015 y 2020). ${ }^{42}$

\section{El Ministerio de Obras Públicas (MOP):}

Tal como mencionamos, en el MOP, un conjunto nutrido de militantes de la TR ocupó los principales cargos y secretarías. A la cabeza de esta dependencia estuvo el Agrimensor e Ingeniero Civil Alberto González, cuya militancia en el peronismo revolucionario y su labor docente en la Facultad de Ciencias Exactas de la UBA lo llevó a entablar una estrecha amistad con Rolando García, participando del armado de las propuestas del CT desde su inicio. Concomitante a este desempeño, su militancia cercana a FAR y Montoneros por esos mismos años lo posicionó de lleno como un cuadro político y técnico destacado para la asunción de roles de gestión pública en el contexto de1973.43

Al igual que en Bienestar Social, la metodología de acción directa y el activismo de los trabajadores -a través de la creación de nuevos mecanismos de intervención en la toma de decisiones dentro de la estructura estatal- estuvieron presentes desde los primeros días como un "sello" de la gestión propiciada por los/as militantesfuncionarios/as de la Tendencia.

Por tomar solo un caso, en la Dirección de Energía de la provincia de Buenos Aires (DEBA), el día 12 de junio 250 trabajadores iniciaron una "toma" del establecimiento. Esta acción fue conducida por la "Agrupación Peronista de trabajadores de DEBA", integrada a la JTP, que se enfrentaba a la conducción de la sección local del Sindicato de Luz y Fuerza. ${ }^{44}$ El objetivo inmediato era asegurar la asunción del Subsecretario de Obras Públicas, Pablo Escolar (cuadro de Montoneros) como interventor interino del organismo, y garantizar la participación de los trabajadores en la orientación de las políticas del sector. En el comunicado

\footnotetext{
${ }^{42}$ El Día, 18/10/1973 “Varias iniciativas agropecuarias consideró el gabinete bonaerense”. La falta de tratamiento en la Legislatura de todos estos proyectos, respondía a la debilidad que los representantes de la TR tenían en el parlamento provincial, en donde la correlación de fuerzas dentro del movimiento peronista nunca fue mayoritaria para este sector, menos aún luego de la salida de Cámpora en el mes de julio (Ferrari-Pozzoni, 2008).

${ }^{43}$ Entrevista de la autora a Marina Siri, San Miguel (2017). El Día, 1/6/1973 “Nombran Ministro de Obras Públicas en la Provincia al Ing. Alberto A. González" y El Día, 2/6/73 "Prestó juramento el titular del Ministerio de Obras Públicas, Ingeniero Alberto A. González". Junto a él, otros compañeros de militancia en el CT y en Montoneros fueron designados en las principales secretarías del MOP: en la Subsecretaría de Obras Públicas estuvo el Ingeniero Pablo Escolar, mano derecha de González y principal responsable político de Montoneros en el Ministerio. El Arquitecto Eduardo Casado fue nombrado en la Subsecretaría de Urbanismo y Vivienda, mientras que Jorge Raúl Blanco en la de Programación. Osvaldo Hugo Di Florio estuvo en la Secretaría General, Silvio Peist en la Dirección de Vialidad y Hugo Roberto Scordato ocupó la Dirección de Investigaciones Tecnológicas. Alejandro Belardone fue nombrado Subdirector de Administración, mientras que José Tamarit y Ricardo Rubio estuvieron al frente de la Dirección de Relaciones Públicas y Prensa, junto a Carlos Collarini en Información y Personal (Tocho, 2020)

${ }^{44}$ CPM - FONDO DIPPBA, División Central de Documentación, Registro y Archivo, Mesa de Referencia, legajo N 15979. Tomo 7.
} 


\section{La revolución desde las instituciones: la participación de la Tendencia Revolucionaria en la gobernación de Buenos Aires (1973). Un aporte para el análisis de la política no armada en los años setenta}

que emitieron las agrupaciones que encabezaron la toma, se explicitaba que la participación activa del pueblo trabajador en la gestión del ministerio, lejos de implicar una más de las medidas "reformistas" del estado burgués, tomaba el significado de ser un momento, una parte integrante de la política revolucionaria misma (en relación con la totalidad del proceso de liberación) al originarse en la voz y participación de todos los trabajadores (Tocho, 2020). ${ }^{45}$

Al respecto, como parte de esta demanda de modificaciones en la estructura de poder del MOP que implicasen transformaciones sustantivas en su dinámica de funcionamiento y toma de decisiones, en el mes de agosto se llevaron a cabo dos medidas significativas.

Por un lado, hacia el interior del Ministerio, se puso en marcha la creación de las denominadas Mesas de Trabajo que buscaban potenciar una intervención más activa de los trabajadores en la formulación y discusión de propuestas sobre políticas públicas, y en la toma de decisiones sobre diversas cuestiones de la vida interna del MOP. Estas mesas funcionarían en cada una de las divisiones del Ministerio, y serían integradas por un Coordinador -elegido por votación directa- y todos los trabajadores del sector. Su modalidad sería de debate y asamblearia, elevándose las propuestas de mayoría y minoría -si las hubiese- a una Mesa de Trabajo Central, que a su vez elevaría las propuestas a las autoridades máximas del MOP (Tocho, 2020). ${ }^{46}$ La segunda iniciativa que se implementó, esta vez dirigida a fortalecer y acelerar el vínculo con la comunidad, fue la creación de la Comisión Ejecutiva de Respuesta Inmediata (CERI). ${ }^{47}$ Esta nueva dependencia tenía la función de receptar los pedidos que los distintos grupos de la JP de La Plata y del gran Buenos Aires realizaban, recogiendo a su vez los reclamos de sus bases barriales sobre temas de infraestructura en general (Robles, 2014).

Estos Comités de Gestión Inmediata comenzaron a funcionar en Vialidad, DEBA y demás dependencias, siguiendo la política ya implementada en otras áreas

\footnotetext{
${ }^{45}$ El Día, 14/6/1973 “Designóse interventor interino en DEBA”. Vale la pena citar algunos tramos de las declaraciones que presentaron los trabajadores y militantes de la TR con motivo de esta acción, la que ubicaban como parte de una política revolucionaria situada desde su labor cotidiana en el Ministerio: "Nosotros queremos una política revolucionaria; nadie pretende objetivos ambiciosos pero inalcanzables; tampoco queremos plantear objetivos mínimos ya que eso sería una política oportunista y meramente reformista. La política que consideramos revolucionaria es la que tiende a crear el hombre nuevo, consciente de que el poder también debe pasar por sus manos y ser capaz de asumir esa responsabilidad. ¿Cuáles son entonces los pasos, métodos, técnicas y tareas que nos permitirán avanzar a fin de lograr la participación de todos los trabajadores en el proceso de liberación?: obtener la ruptura de la burocracia establecida mediante la consulta permanente con todos los sectores de trabajo y a todo nivel, a fin de elaborar juntos una política energética bajo los principios revolución en esta etapa". Esta medida que fue resistida por el sindicalismo ortodoxo, reflejó en ese momento el "triunfo" en la correlación de fuerzas que la TR obtuvo al inicio del gobierno provincial, situación que se verá debilitada en muy pocos meses. El Día, 19/6/1973. "Quehacer sindical. La ocupación de DEBA ha motivado declaraciones"

${ }^{46}$ CPM - FONDO DIPPBA, División Central de Documentación, Registro y Archivo Mesa "B”, Carpeta 4, Legajo N 27, folio 85, 89-90.

47 El Día, 5/10/1973 "Ya funciona el Comité de Gestión Inmediata en el ente Vial”.
} 


\title{
Fernanda Tocho
}

ministeriales. Parte de las obras realizadas por esta Comisión consistió en la colocación de asfalto y arreglo de calles, la extensión de la red cloacal y de los desagües, tendido eléctrico en zonas marginales, etc.

El siguiente testimonio de un militante de Montoneros que trabajó al frente de este programa ejemplifica parte de las acciones llevadas a cabo:

\begin{abstract}
"Llevamos el agua potable a los barrios, que no la pudimos desarrollar del todo porque nos fuimos antes, pero hay muchos barrios que hoy tienen agua potable gracias a nosotros. ¿Cómo funcionaba? Establecimos trabajo voluntario asociado al Ministerio, incluso los propios funcionarios fueron a cavar zanjas junto con los compañeros barriales de la JP para colocar los caños, los ingenieros también fueron... Había un proceso revolucionario desde las instituciones, respetando las instituciones. Nosotros (JP-Montoneros) poníamos el trabajo voluntario, sacamos los técnicos de las oficinas y los llevamos al territorio, y abrimos los galpones y los corralones donde había de todo, el estado puso el material y las máquinas, y la gente ponía el trabajo voluntario y en muchos barrios hicimos eso. ${ }^{48}$
\end{abstract}

Como podemos observar, en el relato de los/as militantes-funcionarios/as, las iniciativas realizadas, las modalidades de trabajo y de gestión implementadas, y también los objetivos proyectados desde su quehacer institucional, lejos de ser pensados como acciones "reformistas" alejadas de los fines estratégicos mayores, comenzaron a ser resignificadas como parte misma de sus tareas revolucionarias y su contribución al proyecto mayor de construcción de la "patria socialista", revalorizando en el curso mismo de esa experiencia de gobierno su intervención política desde el Estado.

Cabe señalar que estas expectativas y nuevos sentidos generados al calor de su labor cotidiana en el gobierno, no dejaron de despertar tensiones al interior de la TR, a raíz del peso mayor que la vía armada como metodología principal comenzó a tener entre la conducción de FAR y Montoneros hacia la segunda mitad del año 1973, y que explicitaron en un famoso documento de discusión interna denominado "Mamotreto" (Salcedo, 2011; Bartoletti, 2012; Pozzoni, 2017). Si bien las nociones allí volcadas sobre el rol de vanguardia, la primacía de la lucha armada y la conformación de un ejército como postulados estratégicos no eran nuevos, comenzaron a cobrar un renovado espesor en una coyuntura cada vez más adversa para los sectores radicalizados del peronismo que comenzaban a ser blanco de las medidas represivas desplegadas desde el propio gobierno nacional. En ese marco, el activismo no armado de los/as militantes-funcionarios/as de la Tendencia comenzó a ser cuestionado desde algunos cuadros de conducción de las organizaciones armadas, quienes "menospreciaban" el trabajo institucional y acompañaban esas críticas con la presión por poner en marcha las prácticas armadas. ${ }^{49}$

\footnotetext{
${ }^{48}$ Entrevista de la autora a Ricardo Rubio, San Miguel (2017)

${ }^{49}$ Entrevista de la autora a Flora Castro (2012), Hugo Bacci (2012), Mabel Maidana (2014), Marina Siri (2016) y Ricardo Rubio (2016)
} 


\section{La revolución desde las instituciones: la participación de la Tendencia Revolucionaria en la gobernación de Buenos Aires (1973). Un aporte para el análisis de la política no armada en los años setenta}

Este accionar que desalentaba la experiencia gubernamental cuestionando su "utilidad" a los fines revolucionarios, socavó internamente la fuerza y las expectativas de quienes apostaron a la tarea político-institucional como parte central de su militancia peronista y revolucionaria. Esta situación, vivida como un dilema por parte de sus protagonistas, no hizo más que profundizarse a partir de las contradicciones políticas de fondo y el enfrentamiento de estos sectores con Perón y la ofensiva represiva que terminó con la renuncia de Bidegain y la expulsión del conjunto de la militancia revolucionaria de los espacios gubernamentales.

\section{Punto de llegada y algunas consideraciones para la investigación}

El gobierno de Bidegain llegó a su fin el 22 de enero de 1974, luego del intento del copamiento de la Guarnición Militar de la localidad de Azul por parte de la guerrilla guevarista del ERP, y el enérgico mensaje de Perón al día siguiente responsabilizando por estos hechos al gobernador bonaerense (Bustingorry, 2015 y Tocho, 2020). Si bien este acontecimiento fue el detonante que precipitó su renuncia y la de todos/as los/las funcionarios/as de la TR, el clima de desestabilización que venía sufriendo su gobierno se había incrementado notablemente en los meses precedentes, en el marco de la "caza de brujas" que la derecha del movimiento venían llevando a cabo contra los militantes de la Tendencia, y que el propio Perón habilitó con la "ofensiva depuratoria" emanada desde el Documento Reservado y el conjunto de medidas represivas tomadas durante su presidencia (Franco, 2012; Merele, 2016).

Como vimos, las tensiones que venía acumulando el gobierno de Bidegain y la TR a pocos meses de su asunción no fueron menores, despertando todo tipo de resistencias (de sectores políticos, sindicales y económicos dentro y fuera del peronismo) que no solamente marcaban los límites para la posibilidad de implementar medidas que trastocaran las estructuras del poder económico vigente, sino también y fundamente, las dificultades para poder llevar a cabo en esa coyuntura metodologías de acción revolucionaria y un proyecto político alternativo con Perón como presidente.

En este sentido el presente artículo se propuso traer a consideración esas experiencias de corte radicalizado que la militancia de la TR -incluso muchos/as como miembros de organizaciones armadas- intentó llevar a cabo en el gobierno bonaerense, más allá de su corta duración o que incluso muchas de ellas solo alcanzaron la etapa de formulación.

De esta forma, al reponer las trayectorias previas de preparación técnica de una gran cantidad de cuadros de la Tendencia que ocuparon cargos relevantes en el gobierno provincial, y la articulación de esas prácticas profesionales con su militancia política revolucionaria, intentamos volver la atención sobre aquellos cursos de acción aún 


\section{Fernanda Tocho}

abiertos y "futuros en pugna" (Barletta, Lenci y Ramírez, 2013) puestos en juego por estos actores en la coyuntura democrática, proyectos que si bien no llegaron a concretarse completamente, dieron cuerpo a un conjunto de sentidos y prácticas renovadas sobre las posibilidades de transformación desde su participación en el Estado.

Así, a través de este recorrido, pudimos observar como para muchos de sus protagonistas, la experiencia inédita de "militancia en el Estado" lejos de presentarse como una disyuntiva escindida de sus objetivos estratégicos mayores y de su pertenencia a las organizaciones armadas, por el contrario, fue resignificada como una instancia sustancial de ese proyecto de más largo alcance, inscribiendo esas prácticas no armadas dentro del universo de sentidos atravesados por la revolución, viendo allí la posibilidad de conjugar un proceso de cambio radical desde las instituciones.

De esto se desprende que, al menos para los actores que formaron parte de esta experiencia, no hubo lógicas dicotómicas o excluyentes, sino apuestas complejas por compatibilizar lo institucional, lo armado y lo revolucionario, en un contexto extremadamente vertiginoso y en el que las relaciones de fuerza dentro del peronismo cambiaron bruscamente a favor de los sectores detractores de la Tendencia, cerrando cada vez más los espacios y las posibilidades de acción desde el ámbito gubernamental. Este escenario y la dinámica política cada vez más represiva hacia el interior del peronismo, propició dentro del heterogéneo conglomerado de la TR la línea sostenida desde siempre por la conducción de las organizaciones político-militares, a favor del proyecto estratégico de lucha armada, en un contexto en el que ya las condiciones favorables para desarrollar políticas institucionales eran escasas por no decir nulas.

Bajo este enfoque, esperamos que este trabajo haya podido contribuir a ampliar el marco de reflexión sobre las distintas expresiones de la política revolucionaria en los años setenta, observando las orientaciones plurales que esta praxis tuvo al interior de la militancia peronista dentro y fuera de Estado, reparando particularmente en las "otras prácticas", las no armadas, que también se inscribieron en ese horizonte de trasformación radical de aquéllos años, más allá de su obturación y derrota política.

\section{Bibliografía}

Abbattista, L. y Ramírez, A. (2011) "Las tomas en la ciudad de La Plata. Aportes al estudio de la dinámica política durante el gobierno de Héctor Cámpora”, ponencia presentada en las XIII Jornadas Interescuelas / Departamentos de Historia, Catamarca, 2011. 


\section{La revolución desde las instituciones: la participación de la Tendencia Revolucionaria en la gobernación de Buenos Aires (1973). Un aporte para el análisis de la política no armada en los años setenta}

Acha, 0. (2010) "Dilemas de una violentología argentina: tiempos generacionales e ideologías en el debate sobre la historia reciente", en V Jornadas de Trabajo sobre Historia Reciente, Universidad Nacional de General Sarmiento, Buenos Aires.

Anzorena, O. (1998) Tiempo de violencia y utopía. Del golpe de Onganía (1966) al golpe de Videla (1976). Buenos Aires. Ediciones del Pensamiento Nacional.

Antúnez, D. (2015) Caras extrañas. La Tendencia Revolucionaria del Peronismo en los gobiernos provinciales (Buenos Aires, Córdoba, Mendoza, Santa Cruz y Salta, 19731974). Prohistoria

Barletta, A. (2018) "Apuntes sobre un legado invisibilizado: Universidad y peronismo en la UNLP, 19721974" en Colección Nuevas Bases Para La Reforma Universitaria. Volumen 4. IEC-CONADU. Recuperado de: http :// iec . conadu . org . ar / files / publicaciones /1540404666_ la plata -1972-1974. pdf

Barletta, A. Lenci, L. y Ramírez, A. (2013) "Democracias en pugna: un intento de recuperar los sentidos perdidos”, Cuestiones de Sociología, № 9, La Plata.

Bartoletti, J. (2011) Montoneros: De la movilización a la Organización. Rosario, Laborde Libros.

Besoky, J. (2010) “La revista El Caudillo de la Tercera Posición: órgano de expresión de la extrema derecha”, en: Conflicto Social, Año 3, № 3, junio de 2010.

Bonasso, M. (2010) El presidente que no fue. Los archivos ocultos del peronismo. Planeta.

Bonavena, P. (2009) "Guerra contra el campo popular en los '70: Juan Domingo Perón, la depuración ideológica y la ofensiva contra los gobernadores" en Izaguirre, I., Lucha de clases, guerra civil y genocidio en la Argentina 1973-1983, Buenos Aires, Eudeba.

Bustingorry, H. (2015) Oscar Bidegain. La fugaz experiencia del pacto social en la provincia de Buenos Aires. Archivo Histórico de la Provincia de Buenos Aires

Calveiro, P. (2005) Política y/o violencia. Una aproximación a la guerrilla de los años 70, Bs. As, Editorial Norma.

Camelli, E. (2018) "Revolución y socialismo nacional en las villas setentistas de Buenos Aires: expropiación de tierras, radicación de villas y empresa popular". Revista Encuentros Uruguayos Volumen XI, Número 1, Julio 2018 pp.: 45 - 58

Chama, M. y Gonzalez Canosa, M. (2011) “Universidad, política y movimiento estudiantil: la Intervención de Kestelboim y el rol de la Juventud Universitaria 


\section{Fernanda Tocho}

Peronista en la Facultad de Derecho de la UBA (1973-1974)", en Revista Conflicto Social, Instituto de Investigaciones Gino Germani, FSC / UBA. Volumen № 5, junio 2011.

Denaday, J. (2018) No todo fue violencia: un think tank en el retorno de Perón. El caso del Consejo de Planificación del Movimiento Nacional Justicialista (1970-1973). Tesis de Maestría, Posgrados en Historia, Departamento de Estudios Históricos y Sociales, Universidad Torcuato Di Tella. Recuperado de: https :// repositorio . utdt . edu / bitstream / handle / utdt /11053/ MHIS _2018_Denaday . pdf ? sequence $=1 \&$ isAllowed $=$

Dip, N. (2017) Libros y alpargatas: la peronización de estudiantes, docentes e intelectuales de la UBA (1966-1974). Rosario: Prohistoria.

Duzdevich, A., Raffoul, N. y Beltramini, R. (2015) La Lealtad. Los Montoneros que se quedaron con Perón. Bs. As. Sudamericana.

Ferrari, M. y Pozzoni, M. (2008) "La legislatura bonaerense (1973-1974): otro espacio de conflicto entre la derecha y la izquierda peronistas". Actas de las $V$ Jornadas de Sociología de la UNLP.

Franco, M. (2012) Un enemigo para la nación. Orden, violencia y “subversión”. 19731976. Bs.As. FCE

Friedemann, S. (2017) “De las Cátedras Nacionales (1967-1971) a la Universidad Nacional y Popular de Buenos Aires (1973-1974). Experiencias configuradoras de institucionalidad universitaria". Sociohistorica, 39, e026. Recuperado de: https://doi.org/10.24215/18521606e026

Gallo Mendoza, G. (2010) La marcha al campo. Propuestas para contribuir a superar la desocupación estructural, Bs. As., Fundación Patagonia Tercer Milenio.

Gasparini, J (1999). Montoneros. Final de cuentas. Editorial De La Campana

Giorgi, G. (2014-2015) "En los pliegues de la planificación del Onganiato: el comunitarismo como política estatal”, en Anuario IEHS, № 29 y 30, pp.159-175.

Giorgi, G. y Mallimacci, F. (2012) “Catolicismos, nacionalismos y comunitarismos en política social. Redes católicas en la creación del Ministerio de Bienestar Social de Argentina (1966-1970)", en Cultura y Religión, Vol.1, № 6, Iquique, pp. 113-144

Lanteri, M. y Meschiany, T. (2015). "Bases para la nueva Universidad. La UNLP entre 1973 y 1976". Ponencia presentada en XI Jornadas de Sociología. Facultad de Ciencias Sociales, Universidad de Buenos Aires. Recuperado de: http :// cdsa . aacademica . org /000-061/922. Pdf 


\section{La revolución desde las instituciones: la participación de la Tendencia Revolucionaria en la gobernación de Buenos Aires (1973). Un aporte para el análisis de la política no armada en los años setenta}

Lattuada, M. (1986) La política agraria peronista (1943-1983). Buenos Aires, CEAL.

Lázzaro, S. (2013) “Acuerdos y confrontaciones: la política agraria peronista en el marco del Pacto Social”, en Historia Critica, No. 51, Bogotá, septiembre-diciembre 2013, 284 pp. issn 0121-1617 pp 145-168

Lenci, M. L. (1999) "Cámpora al gobierno, Perón al poder". La Tendencia Revolucionaria del Peronismo ante las elecciones del 11 de marzo de 1973" en Pucciarelli, A (1999). La primacía de la política. Lanusse, Perón y la Nueva Izquierda en tiempos del GAN, Bs.As. Eudeba.

Merele, H. (2016) "El Germen genera sus propios anticuerpos". La "depuración" interna peronista y el proceso represivo entre 1973-1976. En Gabriela Aguila Dossier. Represión estatal y paraestatal en la historia reciente argentina. Recuperado de:

\section{http://www.historiapolitica.com/datos/biblioteca/represionestatal merele.pdf}

Oberti, A. y Pittaluga, R. (2006), Memorias en montaje. Escrituras de la militancia y pensamientos sobre la historia, Buenos Aires: El cielo por Asalto.

Ollier, M. (2005) Golpe o Revolución. La violencia legitimada, Argentina 1966 /1973. Buenos Aires, Editorial de la Universidad Nacional de Tres de Febrero.

Osuna, F. (2017) La intervención social del estado. El ministerio de bienestar social entre dos dictaduras, Rosario, Prohistoria, 2017

Osuna, F. y Vicente, M. (2017) "Estudios sobre Ministerios. Actores, políticas y problemas de abordaje entre el primer peronismo y la última dictadura" en Estudios Sociales del Estado - volumen 3, número 6, pp. 1 a 10, segundo semestre de 2017 ISSN: 2422-7803

Pastoriza, L. (2006) «La «traición» de Roberto Quieto. Treinta años de silencio». En: Revista Lucha Armada, № 6. Buenos Aires.

Perdía, R. (1997) La otra historia. Testimonio de un jefe montonero, Bs.As, Ágora.

Peyrou, A. (2010) "Lealtad". Anuario Lucha Armada en la Argentina, Año 5, Buenos Aires.

Poupeau, F. (2007) "El capital militante. Intento de definición”, en Poupeau, F., Dominación y movilizaciones. Estudios sociológicos sobre el capital militante y el capital escolar, Ferreyra Editor, Córdoba, pp. 37-44. 


\section{Fernanda Tocho}

Pozzoni, M. (2015) "La participación político-técnica de la izquierda peronista en el ministerio de educación bonaerense (1973-1974)”. En ESTUDIOS - № 34 (Juliodiciembre 2015) pp. 119-137

Pozzoni, M. (2017) Leales. De la Tendencia Revolucionaria del peronismo a la JP Lealtad. Imago Mundi

Ramacciotti K. (2014) "Políticas sanitarias, desarrollo y comunidad en la Argentina de los años sesenta” Rev. Ciencias de la Salud. 2014;12(1):93-113.

Robles, H. (2014). "La retaguardia revolucionaria: Una descripción de la estructura de unidades básicas controlada por la juventud peronista y Montoneros en los barrios populares de la ciudad de La Plata [1972-1974]". En: Tortti, María Cristina; Chama, Mauricio; Celentano, Adrián, dir. La nueva izquierda argentina [1955-1976]: Socialismo, peronismo y revolución. Rosario: Prohistoria.

Rougier M. y Fiszbein M. La frustración de un proyecto económico. El gobierno peronista de 1973-1976, Ed Manantial, Buenos Aires, 2006.

Salcedo, J. (2011) Los Montoneros del barrio. Bs.As. EDUNTREF

Servetto, A. (2010) 73/76; El gobierno peronista contra las "provincias montoneras", BsAs, Siglo XXI.

Slipak, D. (2015) Las revistas montoneras. Cómo la organización construyó su identidad a partir de sus publicaciones, Buenos Aires, Siglo XXI,

Svampa, M. (2003) “El populismo imposible y sus actores, 1973-76" en James, D. (DIR) Violencia, proscripción y autoritarismo (1955-1976), Tomo IX de la Colección Nueva Historia Argentina, Bs. As., Sudamericana.

Svampa, M. (2010) Certezas, incertezas y desmesuras de un pensamiento político. Conversaciones con Floreal Ferrara. Buenos Aires, 2010.

Tocho, F. (2014) 'Los 'otros setenta': un recorrido por la experiencia de la Tendencia Revolucionaria del Peronismo en la gobernación bonaerense (19731974)" en Aletheia. Revista de la Maestría en Historia y Memoria de la FaHCE, volumen 4 , número 8 , abril.

Tocho, F. (2015) "El desafío institucional: las prácticas políticas no armadas de la Tendencia Revolucionaria del Peronismo en el Ministerio de Asuntos Agrarios de la provincia de Buenos Aires (1973-1974)" Sociohistórica. Cuadernos del CISH, FaHCE, UNLP, $\mathrm{N}^{\circ} 35,2015$, pp. 1-22.

Tocho, F. (2018) "No solo lucha armada. El Operativo Dorrego y la participación institucional de la Tendencia Revolucionaria en la provincia de Buenos Aires", en: 
La revolución desde las instituciones: la participación de la Tendencia Revolucionaria en la gobernación de Buenos Aires (1973). Un aporte para el análisis de la política no armada en los años setenta

Encuentros Uruguayos. Revista Digital de la Facultad de Humanidades y Ciencias de la Educación, Universidad de la República, Montevideo. Vol XI, Núm 1. http://www.encuru.fhuce.edu.uy/images/revistas/numero11/07-Tocho.-FINAL. $\mathrm{pdf}$

Tocho, F. (2019) "La Tendencia Revolucionaria del Peronismo en la apertura democrática. Un acercamiento a las experiencias de radicalización "movimientistas" y su posicionamiento frente a la salida electoral (1971-1972). Actas de las XVII Jornadas Interescuelas/Departamentos de Historia, Universidad Nacional de Catamarca.

Tocho, F. (2020) Lógicas políticas en tensión: La Tendencia Revolucionaria del Peronismo y su participación en el gobierno constitucional de la provincia de Buenos Aires (1973-1974). (Tesis de Doctorado inédita). - Presentada en Universidad Nacional de La Plata. Facultad de Humanidades y Ciencias de la Educación.

Urriza, M. (2004) El Perón que conocí. Bs.As., Ediciones Continente.

Recibido: 15/07/2020

Evaluado: $28 / 08 / 2020$

Versión Final: 15/10/2020 